\title{
The relationship between voluntary product (re) formulation commitments and changes in the nutritional quality of products offered by the top packaged food and beverage companies in Canada from 2013 to 2017
}

Laura Vergeer ${ }^{1}$, Mavra Ahmed ${ }^{1}$, Lana Vanderlee ${ }^{1,2}$, Christine Mulligan $^{1}$, Madyson Weippert ${ }^{1}$, Beatriz Franco-Arellano ${ }^{1,3}$, Kacie Dickinson ${ }^{1,4}$, Jodi T. Bernstein ${ }^{1}$, Marie-Ėve Labonté ${ }^{1,2}$ and Mary R. L'Abbé ${ }^{*}$ (1)

\begin{abstract}
Background: Food companies shape Canada's food supply through voluntary actions and commitments concerning product (re)formulation; however, the extent that these initiatives translate into actual improvements in nutritional quality is unclear. This study examined changes in the nutritional quality of products offered by the top 22 packaged food and beverage companies in Canada from 2013 to 2017, in relation to the strength of their product (re) formulation actions and commitments.

Methods: The Food Company Reformulation (FCR) scoring tool was used to quantify the strength of companies' reported recent actions and commitments to reduce energy and nutrients of concern in their products, with higher scores signifying stronger voluntary actions/commitments. Nutritional information for products was sourced from the University of Toronto FLIP 2013 ( $n=6490)$ and 2017 ( $n=8277)$ databases $(n=4074$ matched products). Changes in product healthfulness were assessed using the Health Star Rating (HSR) system (with higher HSRs denoting healthier products) and calories, sodium, saturated fat, trans fat, and total and free sugar levels per $100 \mathrm{~g} / \mathrm{mL}$. Generalized estimating equations examined changes in nutritional quality in relation to FCR scores.

Results: Overall, mean HSRs increased significantly for 5 companies' product portfolios and were reduced in 1 company's product portfolio. There were significant reductions in calories, sodium, saturated fat in 2 companies' portfolios and increases in 4, 3, and 8 companies' portfolios, respectively. Trans fats increased significantly in 2 companies' portfolios. Total and free sugars decreased significantly in 4 and 5 companies' portfolios, respectively, and increased in 1 company's portfolio. There was little change in the healthfulness of matched products. Higher FCR scores were not associated with greater increases in HSRs, or reductions in calories or nutrient amounts. FCR scores were negatively associated with HSRs and positively associated with total and free sugars. No relationship was observed between FCR scores and calories, sodium, saturated fat or trans fat.
\end{abstract}

\footnotetext{
*Correspondence: mary.labbe@utoronto.ca

1 Department of Nutritional Sciences, Temerty Faculty of Medicine,

University of Toronto, 1 King's College Circle, Toronto, Ontario M5S 1A8,

Canada

Full list of author information is available at the end of the article
}

(C) The Author(s) 2022. Open Access This article is licensed under a Creative Commons Attribution 4.0 International License, which permits use, sharing, adaptation, distribution and reproduction in any medium or format, as long as you give appropriate credit to the original author(s) and the source, provide a link to the Creative Commons licence, and indicate if changes were made. The images or other third party material in this article are included in the article's Creative Commons licence, unless indicated otherwise in a credit line to the material. If material is not included in the article's Creative Commons licence and your intended use is not permitted by statutory regulation or exceeds the permitted use, you will need to obtain permission directly from the copyright holder. To view a copy of this licence, visit http://creativecommons.org/licenses/by/4.0/. The Creative Commons Public Domain Dedication waiver (http://creativeco mmons.org/publicdomain/zero/1.0/) applies to the data made available in this article, unless otherwise stated in a credit line to the data. 
Conclusions: Reporting stronger voluntary product (re) formulation actions and commitments was not associated with greater improvements in the healthfulness of products offered by Canada's leading packaged food and beverage companies from 2013 to 2017, suggesting a need for stronger industry initiatives or mandatory government interventions to improve the healthfulness of the food supply.

Keywords: Food company, Reformulation, Nutritional quality, Nutrient profile, Commitment

\section{Background}

Packaged food supplies dominated by energy-dense products containing excessive amounts of saturated fat, sodium and sugars promote poor diet quality and increase consumers' risk of developing obesity and noncommunicable diseases (NCDs) [1]. In Canada, approximately $50 \%$ of average daily energy intakes come from ultra-processed foods, many of which are energy-dense and high in sodium, saturated fat and/or sugars [2-4]. Consequently, Canadians with the highest intakes of ultra- processed foods are more likely to have obesity, and excessive intakes of saturated fats, sodium, added sugars and energy [5-7]. For example, Canadians consume approximately $2760 \mathrm{mg}$ of sodium per day, which is well above the Chronic Disease Risk Reduction Intake of $2300 \mathrm{mg} /$ day [8]. Given the strong influence that food companies have on the nutritional quality of the packaged food supply, the World Health Organization (WHO) recommends that food companies contribute to reducing the prevalence of obesity and diet-related NCDs by reformulating their existing products to improve their nutritional composition and/or introducing healthier products $[9,10]$.

Reformulation of products in the packaged food supply to improve their nutritional quality is a cost-effective policy measure for addressing the obesity and NCD burden [11-13]. Notably, reformulation is likely to have more impact on diet quality than interventions relying on behaviour changes from consumers [14-16]. Reformulation has been shown by systematic reviews of empirical and modeling studies to improve the healthfulness of food purchases, nutrient intakes and health outcomes, particularly for sodium and trans fat $[12,17]$. According to the Organisation for Economic Cooperation and Development, a 20\% calorie reduction in energydense foods high in sugars, sodium and saturated fats in Canada could prevent 387,000 NCDs between 2019 and 2050, save CAD $\$ 339$ million in annual healthcare expenses, and "increase employment and productivity by the equivalent of 15 thousand full-time workers per year" [18]. Reformulation could also prevent 1.1 million annual global cases of CVDs, diabetes and cancer [19].

Previous studies in Canada and elsewhere have demonstrated that many top packaged food and beverage companies have made voluntary commitments to improve the nutritional quality of their products [20-26]. However, the timelines, breadth of coverage across their product portfolio, geographic applicability, transparency and significance of these commitments in the context of public health recommendations vary widely between companies. Many major food and beverage companies in Canada have not established SMART (specific, measurable, attainable, realistic and time-sensitive) reduction targets for sodium, saturated fat, trans fat, sugars and/ or calories/portion sizes as of 2017 [26]. Research has also shown that many of the products offered by major food companies are of relatively poor nutritional quality [24, 25, 27-30]. In Canada, two-thirds of products offered by the leading packaged food and beverage companies were energy-dense and high in sodium, saturated fat and/or sugars in 2017 [3]. These findings are not surprising, given the evidence to suggest the limited impact of government-led voluntary product (re) formulation policies on the healthfulness of the packaged food supply [31, 32]. However, with many companies establishing their own voluntary product (re) formulation commitments - extending beyond government reformulation programs - there is a need to examine whether stronger commitments reported by individual companies translate into greater improvements in the healthfulness of their products [33]. Companies' public reporting of their reformulation progress is often ambiguous, incomplete and measured according to companies' own nutrient profile models or criteria, suggesting a need for independent assessments of companies' performance concerning product (re) formulation [26]. Although the Access to Nutrition Initiative has assessed both the product (re) formulation commitments and the nutritional quality of the product portfolios of several multinational food companies [24, 25, 27], these reports have not tracked longitudinal improvements in companies' product portfolios in relation to their reformulation targets and this work does not include data from the Canadian market. It is also not known whether some companies have reformulated or improved the nutritional quality of their product portfolios without publicly disclosing this information in their corporate reports and websites.

Thus, the purpose of this study was to investigate changes in the nutritional quality of the product portfolios of the top packaged food and beverage companies 
in Canada between 2013 and 2017, in relation to their voluntary product (re) formulation actions and commitments reported over a similar time period.

\section{Methods}

\section{Selection of companies}

Canada's top 22 packaged food and beverage manufacturers were chosen according to their national market shares in these sectors (sourced from Euromonitor International). The study sample included companies with at least $1 \%$ of the national market share in 2016, representing a total of 51.8 and $69.8 \%$ of Canadian packaged food and beverage sales, respectively [34,35]. Only the parent company (e.g., Coca-Cola) was analyzed when both the parent company and one of its subsidiaries had market shares $\geq 1 \%$ (e.g., Coca-Cola and Minute Maid). The sample consisted of 12 multinational companies based in other countries, 8 Canadian manufacturers or subsidiaries, and 2 national retailers with private-label products. The Canadian packaged food and/or beverage market shares, geographic areas served, location of corporate headquarters and types of food and beverage products offered by companies in this sample are summarized elsewhere [26].

\section{Assessment of product (re) formulation actions and commitments}

Data on the voluntary product (re) formulation actions and commitments of the 22 packaged food and beverage companies was gathered as part of the BIA-Obesity Canada 2017 project, which is reported elsewhere [20, 36]. Briefly, information about companies' recent actions and commitments to reduce the sodium, saturated fat, trans fat, sugars and energy content or portion sizes of products reported as of December 31, 2017 was collected from publicly available sources (e.g., company websites, annual and corporate social responsibility reports) and verified by representatives of the sampled companies, where possible $(n=11 / 22,50 \%$ of companies participated).

The Food Company Reformulation (FCR) scoring tool was applied to assess and quantify the strength of the product (re) formulation actions and commitments reported by companies concerning reductions in energy/ portion sizes, sodium, saturated fat, trans fat and (total, added or free) sugars [26]. The FCR tool assesses companies' recent actions and commitments in terms of their breadth of application across their product portfolio, achieved or targeted magnitudes of nutrient/component reduction and their measurability and meaningfulness in relation to public health recommendations, applicability on national and global levels, and transparency in monitoring and reporting of the company's reformulation progress. Companies only or mainly offering beverages were not evaluated on commitments or recent actions concerning sodium, saturated fat or trans fat, given that amounts of these nutrients/components are typically very low in such products (A. Lassonde, Canada Dry Mott's, Coca-Cola, and Ocean Spray Cranberries). Scores for all companies were weighted, with equal weights assigned to each of the 6 domains constituting the nutrient/component scores (e.g., breadth across product portfolio, magnitude of reduction, national/global applicability) and to each nutrient/component in generating the total scores, resulting in scores out of $100 \%$ in total and for each nutrient/component. A detailed description of the FCR scoring tool is provided elsewhere [26] and the weighted scores used in this analysis are shown in Supplementary Table 1 (Additional File 1). A summary of the validity, internal consistency and inter-rater reliability of the FCR tool is provided in Additional File 2.

\section{Food composition data}

The University of Toronto Food Label Information Program (FLIP) database (described elsewhere [37, 38]) was used to examine changes in the nutritional quality of the products offered by the sampled companies in Canada between 2013 and 2017. FLIP is a database of packaged food and beverage product labels collected from four top Canadian grocery chains (including one retail outlet per chain) from May to September of 2013 (Loblaws, Metro, Safeway, Sobeys; $n=15,285$ ) and three grocery chains between June and September of 2017 (Loblaws, Metro, Sobeys; Safeway was acquired by Sobeys in Fall 2013; $n=17,671)$. FLIP contains information including the name, brand, company, ingredients list, and Nutrition Facts table (NFt) displayed on a product. Products were classified based on the food categories outlined in Health Canada's Table of Reference Amounts for Food (TRA) [39]. A comparison of the healthfulness of the products offered by these 22 companies in 2017 has been published elsewhere [3] and was compared to product healthfulness data from 2013 in this study.

\section{Product matching between 2013 and 2017}

Company names provided on food and beverage packages were searched online to determine if they were offered by any of the sampled companies in 2013 and/or 2017. Individual products offered by the sampled companies in both 2013 and 2017 were matched by barcode or manually by identifying products with identical brand and product names, and the same or similar NFts, ingredients lists and/or product packaging. If a 2013 product was relaunched as a new product in 2017 (e.g., with a different name, brand, flavour, etc.), they were not matched. 


\section{Products included in the sample}

Products in FLIP $2013(n=8756)$ and $2017(n=9200)$ that were not offered by any of the sampled companies in either of these years were excluded from the analyses (Supplementary Fig. 1, Additional File 1). Infant/ toddler foods ( $n=2$ in 2013; $n=134$ in 2017), meal replacements and nutritional supplements $(n=34$ in 2013; $n=36$ in 2017), non-alcoholic drink mixers ( $n=3$ in 2013; $n=14$ in 2017), sugar substitutes $(n=7$ in 2017) and products without fibre labelling (which is required for calculating a Health Star Rating (HSR); $n=3$ in 2017) were also excluded. The final analytic sample included a total of 14,767 unique products from FLIP $2013(n=6490)$ and $2017(n=8277)$, of which 4074 products were matched between cycles (Supplementary Fig. 1, Additional File 1).

\section{Assessment of the nutritional quality of products}

The nutritional quality of products offered by the companies in this sample in 2013 and 2017 were evaluated in terms of the HSR system [40] and levels of calories, sodium, saturated fat, trans fat, total sugars and free sugars per $100 \mathrm{~g}$ (or $\mathrm{mL}$ ). Products necessitating the addition of water or other ingredients prior to consumption were assessed according to their nutritional composition "as prepared" (based on directions for preparation provided on the product packaging) to enable comparisons with prepared products within that food category, such as: condensed soups, combination dishes needing preparation; and baking, beverage, sauce, gravy, or dessert powders and mixes. All other products in the sample were assessed based on their nutritional composition "as sold".

\section{HSR system}

The HSR system is a nutrient profile (NP) model that underlies the interpretative front-of-package nutrition labelling system, developed for implementation in Australia and New Zealand [40]. This system was selected for use as a NP model in the present study as a means of summarizing the nutritional quality of foods and beverages because it encompasses both positive and negative nutrients/components. The HSR system also provides a range of scores, which is more useful for comparing the healthfulness of products offered by different companies than binary nutrient profile models that classify products as simply "healthy" or "unhealthy". Additionally, the HSR system is a derivation of previously validated and globally-applied NP models [40, 41], and has been used in similar studies evaluating the healthfulness of products offered by packaged food and beverage manufacturers in other countries [24, 25, 27-30].
Methodology for applying the HSR system to packaged foods and beverages is described in detail elsewhere [40]. Briefly, the HSR system evaluates products based on their energy, saturated fat, sodium, total sugars content, fibre, protein, and fruits, vegetables, nuts and legumes (FVNL) contents per $100 \mathrm{~g}$ or $100 \mathrm{~mL}$ (depending on whether the NFt is listed per $\mathrm{g}$ or $\mathrm{mL}$ ), with nutrient-specific thresholds and algorithms for calculating points that differ by HSR food category. Given that quantitative ingredient declarations are not required on Canadian foods and beverages, a method for estimating the FVNL contents of products using a non-quantitative ingredients list was derived by our group and applied in this study [42]. A final HSR was derived, ranging from 0.5 to 5 stars in 0.5 -star increments. An HSR $\geq 3.5$ was deemed "healthy", based on research by the New South Wales Ministry of Health in Australia, which showed that foods with an HSR $\geq 3.5$ are generally in agreement with Australian dietary guidelines [43]. The $\geq 3.5$ threshold is also consistent with other studies that used the HSR system [24, 25, 27-29, 44, 45].

\section{Calorie and nutrient amounts}

The nutritional quality of products offered by the companies in this sample was also examined in terms of calories, sodium, saturated fat, trans fat, total sugars and free sugars per $100 \mathrm{~g}$ or $100 \mathrm{~mL}$ (depending on whether the relevant TRA minor food category used $\mathrm{g}$ or $\mathrm{mL}$ as the unit). Nutrients/components were examined individually to enable comparisons with nutrient/component sub-scores from the FCR scoring tool, and because they are recommended to limit in the diet and the food supply by the WHO, Health Canada and other public health authorities [46, 47]. Free sugar contents in 2013 and 2017 were approximated using an algorithm derived by Bernstein et al. [37]. Both total and free sugars contents were used since it was not possible to estimate free sugars for some Loblaw and Sobeys private-label products that included an NFt but did not display an ingredients list (e.g., desserts baked in-store; $n=276$ ).

\section{Statistical analyses}

The number and percentage of products that each company offered in 2013 but not 2017 or vice versa, and the number and percentage of the products of each company that were matched between cycles, were calculated. Absolute and percentage changes in mean HSRs and median calories, sodium, saturated fat, trans fat, and total and free sugars per $100 \mathrm{~g}$ (or $\mathrm{mL}$ ) were evaluated in each company's total product portfolio, by TRA food category and for matched products specifically. Changes in the HSRs of matched products were compared to those of unmatched products to examine 
whether observed changes in the nutritional quality of companies' product portfolios were more likely due to reformulation (i.e., matched) versus product development or discontinuation, or acquisitions and sales of products between companies (i.e., unmatched) from 2013 to 2017.

For each company, Mann-Whitney U tests and Pearson chi-squared tests compared HSRs and the proportion of products with an HSR $\geq 3.5$, respectively, between 2013 and 2017. Fisher's exact test was used to compare proportions when $<5$ products had an HSR $\geq 3.5$ in 2013 or 2017. Mann-Whitney $U$ tests were used to compare amounts of calories and nutrients per $100 \mathrm{~g}$ (or $\mathrm{mL}$ ) in companies' product portfolios between 2013 and 2017, while Wilcoxon signed-rank tests compared changes in HSRs and calorie/nutrient contents of matched products.

Generalized estimating equations (GEEs) examined the relationship between changes in the HSRs, and calorie, sodium, saturated fat, trans fat, and total and free sugars contents (per $100 \mathrm{~g}$ or $\mathrm{mL}$ ) of companies' products from 2013 to 2017, and their FCR tool scores. Separate models were constructed with HSR, calories, sodium, saturated fat, trans fat, total sugars and free sugars as outcome variables, with year (2013 or 2017) and FCR tool score (total score for the HSR model or the relevant nutrient/ component sub-score for the other models) as predictors, adjusted for TRA major food category. FCR scores were standardized and entered into the models as a continuous predictor. An interaction term between year and FCR score was used to examine whether the change in HSRs or calorie/nutrient density over time differed between products offered by companies with higher versus lower FCR tool scores. Products matched between 2013 and 2017 were included in the same clusters and an exchangeable working correlation matrix was specified for all models [48]. Model types were selected based on the distribution of the data and the Quasi Likelihood under Independence Model Criterion and Corrected Quasi Likelihood under Independence Model Criterion goodness-of-fit information criteria [48]. For GEE models that used a logarithm link function (i.e., those with calories, sodium, saturated fat or free sugars as the dependent variable), a 1-unit change in a covariate (i.e., year or FCR score) multiplies the mean value of the dependent variable (e.g., calories) by exp.( $\beta$ ). For models with an identity link (i.e., those with HSR, trans fat or total sugars as the dependent variable), exp.( $\beta$ ) is the expected change in the mean of the dependent variable for each change in a covariate. For all analyses, $p$-values $<0.05$ were considered statistically significant. Analyses were completed using RStudio (version 1.2.5019, RStudio Inc., Boston, MA, USA) and IBM SPSS (version 26.0, IBM Corp., Chicago, IL, USA).

\section{Results}

Matched, new and discontinued products

Among the total sample, $49.2 \%(n=4074)$ of products in 2017 were matched to 2013, ranging from 28.0 to $72.2 \%$ of the products offered by a given company in 2017 (Table 1). Newly introduced and acquired products (i.e., collected in FLIP 2017 but not 2013) represented $50.8 \%(n=4203)$ of the 2017 sample, ranging from 34.2 to $72.0 \%$ of a company's product portfolio. Products that were discontinued or sold to another company (outside the sample) between 2013 and 2017 (i.e., included in FLIP 2013 but not 2017) constituted 37.2\% of the 2013 sample $(n=2416)$, ranging from 16.9 to $57.4 \%$ between companies.

\section{Changes in the healthfulness of companies' products from 2013 to 2017}

Absolute and percentage changes in mean HSRs from 2013 to 2017 are presented for companies' total product portfolios in Table 2, and by matched versus unmatched products in Table 3. Similarly, changes in median calorie and nutrient amounts per $100 \mathrm{~g} / \mathrm{mL}$ are presented for companies' total product portfolios in Table 4, and for matched products in Table 5. Changes in mean HSRs and median calorie/nutrient amounts among total products in each food category are shown in Supplementary Table 2 (Additional File 1), and for matched products in Supplementary Table 3 (Additional File 1). HSRs, calorie and nutrient amounts in companies' products in 2013 are presented by food category in Supplementary Table 4 (Additional File 1); 2017 values have been published elsewhere [3], but were used for these analyses.

\section{HSR system}

Five companies (Kraft Heinz, Loblaws, Mondelēz, Saputo, Sobeys) had significantly higher HSRs and a greater proportion of products with an HSR $\geq 3.5$ in 2017 than 2013 (Table 2). HSRs were reduced significantly in Danone products, and the proportion of products with an HSR $\geq 3.5$ decreased for Canada Bread. Among matched products (Table 3), there were significant changes in the HSRs of products offered by 9 companies, with mean increases in the products of 7 companies and a mean decrease in 1 company's products; however, median absolute and percentage changes in HSRs of matched products were 0.0 and $0.0 \%$, respectively (Table 3 ). Unmatched products (e.g., discontinued or new) demonstrated larger absolute and percentage changes in mean HSRs; significant increases were observed for the products of 6 companies, and decreases for 4 companies (Table 3). 
Table 1 The number of products offered by top packaged food and beverage companies in Canada in 2013 and 2017

\begin{tabular}{|c|c|c|c|c|c|c|c|c|}
\hline \multirow[t]{2}{*}{ Company } & \multicolumn{2}{|c|}{ Total products $(n)^{a}$} & \multicolumn{2}{|c|}{ Matched products ${ }^{\mathrm{b}, \mathrm{c}}$} & \multicolumn{2}{|c|}{$\begin{array}{l}\text { Products discontinued or sold } \\
\text { to other companies }{ }^{d}\end{array}$} & \multicolumn{2}{|c|}{$\begin{array}{l}\text { New or acquired } \\
\text { products } \mathrm{e}^{\mathrm{e}}\end{array}$} \\
\hline & 2013 & 2017 & $\mathrm{n}$ & $\%$ & $\mathbf{n}$ & $\%$ & $\mathrm{n}$ & $\%$ \\
\hline OVERALL & 6490 & 8277 & 4074 & 49.2 & 2416 & 37.2 & 4203 & 50.8 \\
\hline A. Lassonde & 55 & 77 & 35 & 45.5 & 20 & 36.4 & 42 & 54.5 \\
\hline Agropur & 99 & 123 & 53 & 43.1 & 46 & 46.5 & 70 & 56.9 \\
\hline Campbell Soup & 197 & 222 & 116 & 52.3 & 81 & 41.1 & 106 & 47.7 \\
\hline Canada Bread & 101 & 96 & 48 & 50.0 & 58 & 57.4 & 42 & 43.8 \\
\hline Canada Dry Mott's & 50 & 64 & 40 & 62.5 & 10 & 20.0 & 24 & 37.5 \\
\hline Coca-Cola & 83 & 138 & 68 & 49.3 & 14 & 16.9 & 70 & 50.7 \\
\hline Danone & 63 & 132 & 37 & 28.0 & 26 & 41.3 & 95 & 72.0 \\
\hline General Mills & 300 & 382 & 194 & 50.8 & 106 & 35.3 & 188 & 49.2 \\
\hline George Weston & 104 & 169 & 65 & 38.5 & 39 & 37.5 & 104 & 61.5 \\
\hline Kellogg & 129 & 138 & 84 & 60.9 & 45 & 34.9 & 54 & 39.1 \\
\hline Kraft Heinz ${ }^{f}$ & 612 & 460 & 332 & 72.2 & 240 & 39.2 & 168 & 36.5 \\
\hline Loblaw & 2260 & 3099 & 1479 & 47.7 & 781 & 34.6 & 1620 & 52.3 \\
\hline Maple Leaf Foods & 178 & 158 & 90 & 57.0 & 88 & 49.4 & 68 & 43.0 \\
\hline Mondelēz & 45 & 227 & 68 & 30.0 & 17 & 37.8 & 119 & 52.4 \\
\hline Nestlé & 277 & 313 & 158 & 50.5 & 120 & 43.3 & 155 & 49.5 \\
\hline Ocean Spray & 32 & 38 & 25 & 65.8 & 7 & 21.9 & 13 & 34.2 \\
\hline Parmalat & 72 & 120 & 41 & 34.2 & 31 & 43.1 & 79 & 65.8 \\
\hline PepsiCo & 267 & 340 & 199 & 58.5 & 68 & 25.5 & 141 & 41.5 \\
\hline Saputo & 78 & 95 & 36 & 37.9 & 37 & 47.4 & 65 & 68.4 \\
\hline Sobeys & 1248 & 1633 & 754 & 46.2 & 494 & 39.6 & 879 & 53.8 \\
\hline Sun-Rype & 40 & 36 & 19 & 52.8 & 21 & 52.5 & 17 & 47.2 \\
\hline Unilever & 200 & 217 & 133 & 61.3 & 67 & 33.5 & 84 & 38.7 \\
\hline
\end{tabular}

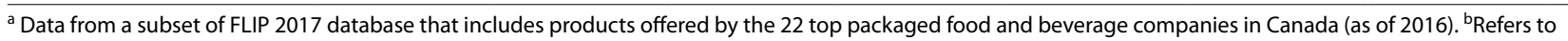
products that were matched between the FLIP 2013 and 2017 datasets (based on barcode, product name, brand, company, Nutrition Facts table, ingredients list, product packaging); products may or may not have been reformulated. ${ }^{\top}$ The percentage of products in FLIP 2017 that were matched to FLIP $2013 .{ }^{d}$ The number and percentage of products offered in 2013 but not 2017, such as due to discontinuation or acquisition of the product by another company; alternatively, products may have not been captured in FLIP 2017 despite being offered by one of the sampled companies at the time of data collection. ${ }^{\mathrm{e} T h e}$ number and percentage of products in 2017 but not 2013, such as due to the introduction of new products or acquisition of products from another company; alternatively, products may have not been captured in FLIP 2013 despite being offered by one of the sampled companies at the time of data collection. In 2013, Kraft Foods and Heinz were two separate companies prior to merging in 2015 and forming The Kraft Heinz Company. However, to enable examination of changes in the nutritional quality of the company's products over time - and because Kraft Heinz was assessed as one company using the FCR scoring tool - Kraft and Heinz were treated as a single company in 2013, as was done in similar research conducted on the Australian market [24]

\section{Calories per $100 \mathrm{~g}$ (or $\mathrm{mL}$ )}

Between 2013 and 2017, calorie contents decreased significantly in the products of 2 companies (Coca-Cola, Kraft Heinz) and increased in the products of 4 companies (Canada Bread, Danone, General Mills, George Weston) (Table 4). For matched products, the amount of calories per $100 \mathrm{~g}$ (or $\mathrm{mL}$ ) changed significantly for 13 companies, although median absolute and percentage changes were $0 \mathrm{kcal}$ and $0 \%$, respectively (Table 5).

\section{Sodium per $100 \mathrm{~g}$ ( $\mathrm{or} \mathrm{mL}$ )}

Sodium levels decreased significantly in the products of 2 companies (A. Lassonde, Loblaw) and increased for 3 companies (Campbell Soup, Danone, Mondelēz)
(Table 4). Sodium contents of matched products decreased significantly for 3 companies (A. Lassonde, Mondelēz, Unilever) and increased in Danone products (Table 5). Ten companies had significant changes in sodium per $100 \mathrm{~g}$ (or $\mathrm{mL}$ ) for matched products, with median absolute and percentage changes of $0 \mathrm{mg}$ and $0 \%$, respectively.

\section{Saturated fat per $100 \mathrm{~g}$ (or $\mathrm{mL}$ )}

Five companies had a median saturated fat content of $0 \mathrm{~g}$ in their product portfolios in 2013 and 2017 (A. Lassonde, Canada Dry Mott's, Coca-Cola, Ocean Spray, Sun-Rype; Table 4). Saturated fat levels decreased significantly in the products of 2 companies (Kraft Heinz, Mondelēz), and increased in the products of 8 companies 
Table 2 Changes in the mean Health Star Rating (HSR) and proportion of the total products offered by each of the sampled companies with an HSR $\geq 3.5$ between 2013 and 2017

\begin{tabular}{|c|c|c|c|c|c|c|c|c|c|}
\hline \multirow[t]{2}{*}{ Company } & \multicolumn{2}{|c|}{ Products (n) } & \multirow{2}{*}{$\begin{array}{l}\text { Mean HSR } \\
\text { (SD) in } 2013\end{array}$} & \multirow{2}{*}{$\begin{array}{l}\text { Mean HSR } \\
\text { (SD) in } 2017\end{array}$} & \multicolumn{2}{|c|}{$\Delta$ Mean HSR } & \multirow[t]{2}{*}{$p$-value ${ }^{*}$} & \multirow{2}{*}{$\begin{array}{l}\text { Absolute } \Delta \text { in } \% \text { of } \\
\text { products with } H S R \geq 3.5 \\
\text { (\%) }\end{array}$} & \multirow[t]{2}{*}{$p$-value ${ }^{* *}$} \\
\hline & 2013 & 2017 & & & Absolute & $\%^{a}$ & & & \\
\hline A. Lassonde & 55 & 77 & $2.3(1.1)$ & $2.3(0.9)$ & 0.0 & 2.0 & 0.091 & -3.6 & 0.70 \\
\hline Agropur & 99 & 123 & $3.6(1.4)$ & $3.6(1.3)$ & 0.0 & 0.5 & 0.85 & 5.9 & 0.44 \\
\hline Campbell Soup & 197 & 222 & $3.1(0.8)$ & $3.2(0.8)$ & 0.1 & 3.2 & 0.43 & -0.4 & 1.00 \\
\hline Canada Bread & 101 & 96 & $3.5(0.7)$ & $3.0(1.3)$ & -0.4 & -12.4 & 0.25 & -14.6 & 0.03 \\
\hline Canada Dry Mott's & 50 & 64 & $2.3(1.3)$ & $2.1(1.2)$ & -0.2 & -9.2 & 0.37 & -10.6 & 0.30 \\
\hline Coca-Cola & 83 & 138 & $2.3(1.4)$ & $2.2(1.3)$ & -0.2 & -7.0 & 0.55 & -4.5 & 0.50 \\
\hline Danone & 63 & 132 & $3.9(0.9)$ & $3.5(1.0)$ & -0.4 & -10.1 & 0.03 & -1.8 & 0.94 \\
\hline General Mills & 300 & 382 & $2.9(1.3)$ & $2.8(1.3)$ & -0.1 & -5.1 & 0.20 & -4.0 & 0.32 \\
\hline George Weston & 104 & 169 & $3.3(0.9)$ & $3.2(0.9)$ & -0.1 & -3.3 & 0.22 & -6.5 & 0.33 \\
\hline Kellogg & 129 & 138 & $2.9(1.1)$ & $2.8(1.1)$ & -0.1 & -2.9 & 0.54 & -0.8 & 1.00 \\
\hline Kraft Heinz ${ }^{b}$ & 612 & 460 & $2.2(1.1)$ & $2.9(1.3)$ & 0.7 & 31.1 & $<0.001$ & 23.6 & $<0.001$ \\
\hline Loblaw & 2260 & 3099 & $2.9(1.2)$ & $3.1(1.3)$ & 0.2 & 7.5 & $<0.001$ & 8.9 & $<0.001$ \\
\hline Maple Leaf Foods & 178 & 158 & $2.3(1.1)$ & $2.3(1.1)$ & 0.0 & -0.1 & 0.91 & 0.7 & 0.99 \\
\hline Mondelēz & 45 & 227 & $1.2(0.9)$ & $1.9(1.1)$ & 0.7 & 58.0 & $<0.001$ & 12.8 & $0.01 *$ \\
\hline Nestlé & 277 & 313 & $2.4(1.0)$ & $2.4(1.1)$ & 0.0 & 0.4 & 0.92 & -3.5 & 0.36 \\
\hline Ocean Spray & 32 & 38 & $2.5(1.0)$ & $2.9(1.2)$ & 0.3 & 12.8 & 0.28 & 8.6 & $0.53^{*}$ \\
\hline Parmalat & 72 & 120 & $3.3(1.3)$ & $3.0(1.4)$ & -0.4 & -10.8 & 0.091 & -4.4 & 0.65 \\
\hline PepsiCo & 267 & 340 & $2.7(1.1)$ & $2.6(1.1)$ & -0.1 & -3.7 & 0.20 & 0.0 & 1.00 \\
\hline Saputo & 78 & 95 & $2.3(1.6)$ & $3.1(1.6)$ & 0.8 & 33.2 & 0.007 & 22.7 & 0.005 \\
\hline Sobeys & 1248 & 1633 & $2.8(1.2)$ & $2.9(1.2)$ & 0.1 & 3.3 & 0.02 & 4.4 & 0.02 \\
\hline Sun-Rype & 40 & 36 & $2.6(1.0)$ & $2.4(0.7)$ & -0.2 & -8.1 & 0.63 & -11.9 & $0.16^{*}$ \\
\hline Unilever & 200 & 217 & $2.8(0.8)$ & $2.8(0.8)$ & 0.0 & 0.3 & 0.93 & 3.0 & 0.57 \\
\hline
\end{tabular}

a Percentage change was calculated by dividing the difference in mean HSRs between 2013 and 2017 by the mean HSR in 2013 , multiplied by 100 . *Results of MannWhitney U tests; $p$-values $<0.05$ were considered statistically significant (shown in boldface). ${ }^{\mathrm{b}}$ In 2013 , Kraft Foods and Heinz were two separate companies prior to merging in 2015 and forming The Kraft Heinz Company. However, to enable examination of changes in the nutritional quality of the company's products over time - and because Kraft Heinz was assessed as one company using the FCR scoring tool - Kraft and Heinz were treated as a single company in 2013, as was done in similar research conducted on the Australian market [24]. ${ }^{* *}$ Results of Pearson chi-squared tests; an asterisk indicates that the Fisher's exact test was used instead due to small group sizes; $p$-values $<0.05$ were considered statistically significant (shown in boldface)

(Campbell Soup, Canada Bread, Danone, General Mills, Kellogg, Parmalat, Saputo, Sobeys). Saturated fat levels in matched products offered by Mondelēz decreased, and changed significantly for 6 companies despite median absolute and percentage changes of $0 \mathrm{~g}$ and $0 \%$, respectively (Table 5).

\section{Trans fat per $100 \mathrm{~g}$ (or $\mathrm{mL}$ )}

Eighteen companies had a median trans fat content of $0 \mathrm{~g}$ in their product portfolios in 2013 and 2017 (Table 4). Trans fat contents increased significantly in products offered by 2 companies (Parmalat, Saputo). Five companies had significant changes in the distribution of trans fat but experienced no change in median trans fat contents per $100 \mathrm{~g}$ (or $\mathrm{mL}$ ). Trans fat contents were reduced significantly in the matched products offered by 3 companies (General Mills, Mondelēz, Unilever) and changed significantly for 3 companies that had median absolute and percentage changes of $0 \mathrm{~g}$ and $0 \%$, respectively (Table 5).

\section{Total sugars per $100 \mathrm{~g}$ (or $\mathrm{mL}$ )}

Total sugars levels decreased significantly in the product portfolios of 4 companies (Kraft Heinz, Loblaw, Mondelēz, Saputo), and increased in Canada Bread products (Table 4). The distribution of total sugars changed significantly in A. Lassonde products despite median absolute and percentages changes of $0 \mathrm{~g}$ and $0 \%$, respectively. Total sugars in matched products changed significantly for 6 companies, yet median absolute and percentage changes were $0 \mathrm{~g}$ and $0 \%$, respectively (Table 5).

\section{Free sugars per $100 \mathrm{~g}$ (or $\mathrm{mL}$ )}

Free sugars contents decreased significantly in the products offered by 5 companies (Kraft Heinz, Loblaw, 
Table 3 Mean and median changes in Health Star Ratings (HSRs) of matched products - and changes in mean HSRs of unmatched products - between 2013 and $2017^{1}$

\begin{tabular}{|c|c|c|c|c|c|c|c|c|c|c|}
\hline \multirow[t]{3}{*}{ Company } & \multicolumn{5}{|c|}{ Matched products ${ }^{1}$} & \multicolumn{5}{|l|}{ Unmatched products } \\
\hline & \multicolumn{2}{|c|}{ Mean $\Delta \mathrm{HSR}^{2}$} & \multicolumn{2}{|c|}{$\begin{array}{l}\text { Median } \\
\Delta \mathrm{HSR}^{2}\end{array}$} & \multirow[t]{2}{*}{$p$-value ${ }^{3}$} & \multicolumn{2}{|l|}{ Mean (SD) HSR } & \multicolumn{2}{|c|}{$\begin{array}{l}\text { Change in } \\
\text { mean } \mathrm{HSR}^{4}\end{array}$} & \multirow[t]{2}{*}{$p$-value ${ }^{5}$} \\
\hline & Abs. & $\%$ & Abs. & $\%$ & & $\begin{array}{l}\text { Products discontinued/sold } \\
\text { to other companies (2013) }\end{array}$ & $\begin{array}{l}\text { New/acquired } \\
\text { products (2017) }\end{array}$ & Abs. & $\%$ & \\
\hline A. Lassonde & -0.2 & -3.2 & 0.0 & 0.0 & 0.27 & $2.0(0.8)$ & $2.4(0.9)$ & 0.4 & 20.0 & 0.005 \\
\hline Agropur & -0.2 & 8.9 & 0.0 & 0.0 & 0.35 & $3.2(1.5)$ & $3.5(1.2)$ & 0.3 & 8.7 & 0.44 \\
\hline Campbell Soup & 0.0 & -0.4 & 0.0 & 0.0 & 0.21 & $3.0(0.9)$ & $3.3(1.0)$ & 0.3 & 8.7 & 0.14 \\
\hline Canada Bread & 0.0 & -0.2 & 0.0 & 0.0 & 0.51 & $3.5(0.7)$ & $3.3(1.3)$ & -0.2 & -6.8 & 0.55 \\
\hline Canada Dry Mott's & 0.0 & 1.7 & 0.0 & 0.0 & 0.41 & $2.6(1.3)$ & $1.9(1.3)$ & -0.7 & -25.5 & 0.18 \\
\hline Coca-Cola & 0.1 & 6.0 & 0.0 & 0.0 & 0.31 & $2.2(1.2)$ & $1.9(1.0)$ & -0.3 & -14.2 & 0.24 \\
\hline Danone & 0.0 & 0.3 & 0.0 & 0.0 & 1.00 & $4.3(0.9)$ & $3.4(1.1)$ & -0.8 & -18.9 & 0.001 \\
\hline General Mills & 0.0 & 2.0 & 0.0 & 0.0 & 0.10 & $3.3(1.3)$ & $2.8(1.2)$ & -0.5 & -16.2 & $<0.001$ \\
\hline George Weston & 0.0 & -0.5 & 0.0 & 0.0 & 0.89 & $3.5(0.8)$ & $3.2(0.9)$ & -0.3 & -8.1 & 0.06 \\
\hline Kellogg & 0.0 & 1.5 & 0.0 & 0.0 & 0.24 & $3.0(1.1)$ & $2.7(1.0)$ & -0.3 & -10.1 & 0.13 \\
\hline Kraft Heinz ${ }^{6}$ & 0.7 & 44.4 & 0.0 & 0.0 & $<0.001$ & $2.3(1.1)$ & $2.7(1.1)$ & 0.5 & 20.1 & $<0.001$ \\
\hline Loblaw & 0.1 & 8.8 & 0.0 & 0.0 & $<0.001$ & $2.7(1.2)$ & $3.1(1.2)$ & 0.4 & 13.3 & $<0.001$ \\
\hline Maple Leaf Foods & 0.1 & 8.6 & 0.0 & 0.0 & 0.03 & $2.6(1.1)$ & $2.6(1.2)$ & 0.0 & -0.8 & 0.99 \\
\hline Mondelēz & 0.2 & 20.2 & 0.0 & 0.0 & $<0.001$ & $0.9(0.6)$ & $2.0(1.2)$ & 1.1 & 116.6 & $<0.001$ \\
\hline Nestlé & 0.1 & 6.9 & 0.0 & 0.0 & 0.003 & $2.6(1.0)$ & $2.4(1.0)$ & -0.1 & -5.2 & 0.21 \\
\hline Ocean Spray & 0.6 & 34.1 & 0.0 & 0.0 & 0.04 & $2.6(1.2)$ & $2.4(1.0)$ & -0.1 & -5.8 & 0.97 \\
\hline Parmalat & 0.0 & 22.4 & 0.0 & 0.0 & 0.96 & $3.8(1.0)$ & $3.0(1.5)$ & -0.9 & -23.0 & 0.004 \\
\hline PepsiCo & 0.0 & 0.9 & 0.0 & 0.0 & 0.72 & $2.7(1.1)$ & $2.4(1.1)$ & -0.3 & -9.9 & 0.047 \\
\hline Saputo & -0.3 & -14.3 & 0.0 & 0.0 & 0.04 & $2.0(1.6)$ & $3.2(1.6)$ & 1.1 & 55.7 & 0.004 \\
\hline Sobeys & 0.1 & 7.0 & 0.0 & 0.0 & $<0.001$ & $2.8(1.1)$ & $2.9(1.3)$ & 0.1 & 3.6 & 0.051 \\
\hline Sun-Rype & 0.0 & 0.0 & 0.0 & 0.0 & N/A & $2.6(1.1)$ & $2.2(0.4)$ & -0.4 & -16.9 & 0.52 \\
\hline Unilever & 0.1 & 8.2 & 0.0 & 0.0 & 0.001 & $2.6(0.8)$ & $2.5(0.7)$ & -0.1 & -5.6 & 0.09 \\
\hline
\end{tabular}

${ }^{1}$ Individual products offered by the sampled companies in both 2013 and 2017 were matched either by barcode or manually by identifying products with identical brand and product names, and the same or similar Nutrition Facts tables, ingredients lists and product packaging. Unmatched products refer to those collected in either 2013 or 2017 , but not both years (e.g., newly developed or acquired products, or products that were discontinued or sold to companies not included in this sample). ${ }^{2}$ Absolute and percentage changes were calculated based on the 2013 and 2017 HSRs of each matched product (by dividing the difference in 2013 and 2017 HSRs by the 2013 HSR, multiplied by 100), and then averaged across all products to generate mean and median absolute and percentage changes. ${ }^{3}$ Results of Wilcoxon signed-rank tests; $p$-values $<0.05$ were considered statistically significant (shown in boldface). ${ }^{4}$ Absolute and percentage changes were determined based on the mean HSRs for all unmatched products in 2013 and 2017; percentage change was calculated by dividing the difference between mean HSRs in 2013 and 2017 by the mean HSR in 2013, multiplied by $100 .{ }^{5}$ Results of Mann-Whitney U tests; $p$-values $<0.05$ were considered statistically significant (shown in boldface). ${ }^{6}$ In 2013 , Kraft Foods and Heinz were two separate companies prior to merging in 2015 and forming The Kraft Heinz Company. However, to enable examination of changes in the nutritional quality of the company's products over time - and because Kraft Heinz was assessed as one company using the FCR scoring tool - Kraft and Heinz were treated as a single company in 2013, as was done in similar research conducted on the Australian market [24]

Mondelēz, Saputo, Sobeys), and increased in Canada Bread products (Table 4). The distribution of free sugars changed significantly in A. Lassonde products, despite median absolute and percentages changes of $0 \mathrm{~g}$ and $0 \%$, respectively. Among matched products, free sugars contents decreased significantly for 3 companies (Agropur, General Mills, Nestlé), increased for 2 companies (Canada Bread, George Weston), and changed significantly in A. Lassonde's matched products but with median absolute and percentage changes of $0 \mathrm{~g}$ and $0 \%$, respectively (Table 5).
Changes in nutritional quality in relation to FCR tool scores A detailed comparison of FCR scores and absolute changes in mean HSRs is provided in Fig. 1. Figure 2 shows absolute changes in mean HSRs and median calorie, sodium, saturated fat, trans fat and free sugars per $100 \mathrm{~g}$ (or $\mathrm{mL}$ ) in companies' product portfolios between 2013 and 2017, presented according to FCR score. GEE results are presented in Table 6 and described below.

\section{HSRs and FCR tool total scores}

HSRs were higher in 2017 than $2013(\exp (\beta)=1.095$, $p<0.001)$. Higher FCR total scores were associated with 
Table 4 Absolute and percentage changes in median calories, sodium, saturated fat, trans fat, total sugars and free sugars per $100 \mathrm{~g}$ (or $\mathrm{mL}$ ) in the product portfolios of the sampled companies between 2013 and 2017., 2

\begin{tabular}{|c|c|c|c|c|c|c|c|c|c|c|c|c|c|c|c|c|c|c|c|c|}
\hline \multirow[b]{2}{*}{ Company } & \multicolumn{2}{|c|}{ Products (n) } & \multicolumn{3}{|c|}{$\Delta{\text { Median calories }(\mathrm{kcal})^{1}}^{1}$} & \multicolumn{3}{|c|}{$\Delta$ Median sodium $(\mathrm{mg})^{1}$} & \multicolumn{3}{|c|}{$\Delta$ Median saturated fat (g) ${ }^{1}$} & \multicolumn{3}{|c|}{$\Delta$ Median trans fat (g) ${ }^{1}$} & \multicolumn{3}{|c|}{$\Delta{\text { Median total sugars }(\mathrm{g})^{1}}^{1}$} & \multicolumn{3}{|c|}{$\Delta$ Median free sugars $(\mathrm{g})^{1}$} \\
\hline & 2013 & 2017 & Abs. & $\%$ & $\begin{array}{c}\text { p- } \\
\text { value }\end{array}$ & Abs. & $\%$ & $\begin{array}{c}\text { p- } \\
\text { value }\end{array}$ & Abs. & $\%$ & $\begin{array}{c}\text { p- } \\
\text { value }\end{array}$ & Abs. & $\%$ & $\begin{array}{c}\text { p- } \\
\text { value }\end{array}$ & Abs. & $\%$ & $\begin{array}{c}\text { p- } \\
\text { value }\end{array}$ & Abs. & $\%$ & $\begin{array}{c}\text { p- } \\
\text { value }^{3}\end{array}$ \\
\hline A. Lassonde & 55 & 77 & 0 & 0 & 0.45 & -4 & -40 & $<0.001$ & 0.0 & $\mathrm{~N} / \mathrm{A}^{4}$ & - & 0.0 & $\mathrm{~N} / \mathrm{A}^{4}$ & - & 0.0 & 0.0 & 0.04 & 0.0 & 0.0 & 0.04 \\
\hline Agropur & 99 & 123 & -12 & -12 & 0.60 & -18 & -27 & 0.08 & -0.2 & -10.0 & 0.74 & -0.1 & -100.0 & 0.94 & 0.0 & 0.0 & 0.27 & 0.0 & $\mathrm{~N} / \mathrm{A}^{4}$ & 0.51 \\
\hline Campbell Soup & 197 & 222 & 4 & 8 & 0.13 & 24 & 9 & 0.01 & 0.2 & 100.0 & 0.03 & 0.0 & $\mathrm{~N} / \mathrm{A}^{4}$ & 0.01 & 0.0 & 0.0 & 0.98 & -0.1 & -14.7 & 0.53 \\
\hline Canada Bread & 101 & 96 & 14 & 5 & $<0.001$ & -16 & -4 & 0.57 & 0.2 & 26.8 & 0.03 & 0.0 & $\mathrm{~N} / \mathrm{A}^{4}$ & 0.05 & 0.3 & 11.1 & 0.03 & 1.2 & 103.4 & $<0.001$ \\
\hline $\begin{array}{l}\text { Canada Dry } \\
\text { Mott's }\end{array}$ & 50 & 64 & -1 & -3 & 0.93 & 0 & 0 & 0.49 & 0.0 & $\mathrm{~N} / \mathrm{A}^{4}$ & - & 0.0 & $\mathrm{~N} / \mathrm{A}^{4}$ & - & 0.0 & -0.3 & 0.73 & -1.5 & -33.1 & 0.69 \\
\hline Coca-Cola & 83 & 138 & -5 & -11 & 0.04 & 0 & 0 & 0.62 & 0.0 & $\mathrm{~N} / \mathrm{A}^{4}$ & 0.44 & 0.0 & $\mathrm{~N} / \mathrm{A}^{4}$ & - & 0.0 & 0.0 & 0.07 & 0.0 & 0.0 & 0.07 \\
\hline Danone & 63 & 132 & 10 & 11 & 0.007 & 9 & 21 & 0.002 & 0.4 & 42.9 & $<0.001$ & 0.0 & $\mathrm{~N} / \mathrm{A}^{4}$ & $<0.001$ & 0.0 & 0.0 & 0.42 & 0.4 & 5.8 & 0.35 \\
\hline General Mills & 300 & 382 & 48 & 20 & 0.009 & 5 & 2 & 0.99 & 0.3 & 18.8 & 0.003 & 0.0 & $\mathrm{~N} / \mathrm{A}^{4}$ & 0.01 & 1.4 & 14.3 & 0.05 & 1.5 & 22.3 & 0.35 \\
\hline George Weston & 104 & 169 & 13 & 5 & 0.003 & 5 & 1 & 0.99 & 0.1 & 12.5 & 0.60 & 0.0 & $\mathrm{~N} / \mathrm{A}^{4}$ & 0.77 & -0.1 & -1.8 & 0.96 & 0.1 & 6.6 & 0.36 \\
\hline Kellogg & 129 & 138 & 4 & 1 & 0.47 & 0 & 0 & 0.43 & 0.8 & 58.6 & 0.02 & 0.0 & $\mathrm{~N} / \mathrm{A}^{4}$ & 0.56 & -1.3 & -6.4 & 0.61 & -2.3 & -12.8 & 0.37 \\
\hline Kraft Heinz ${ }^{5}$ & 612 & 460 & -92 & -35 & $<0.001$ & 33 & 7 & 0.33 & -1.3 & -49.3 & 0.01 & 0.0 & $\mathrm{~N} / \mathrm{A}^{4}$ & 0.28 & -1.2 & -18.3 & $<0.001$ & -4.5 & -100.0 & $<0.001$ \\
\hline Loblaw & 2260 & 3099 & 0.0 & 0.0 & 0.60 & -15 & -5 & 0.002 & 0.0 & 2.0 & 0.31 & 0.0 & $\mathrm{~N} / \mathrm{A}^{4}$ & 0.83 & -0.6 & -14.3 & 0.03 & -0.6 & -56.4 & 0.002 \\
\hline Maple Leaf Foods & 178 & 158 & 1 & 1 & 0.41 & -5 & -1 & 0.52 & -0.4 & -8.9 & 0.98 & 0.0 & $\mathrm{~N} / \mathrm{A}^{4}$ & 0.80 & -0.1 & -6.4 & 0.93 & 0.0 & $\mathrm{~N} / \mathrm{A}^{4}$ & 0.69 \\
\hline Mondelēz & 45 & 227 & -16 & -3 & 0.18 & 233 & 303 & $<0.001$ & -7.3 & -62.7 & 0.01 & 0.0 & $\mathrm{~N} / \mathrm{A}^{4}$ & $<0.001$ & -27.1 & -52.0 & $<0.001$ & -27.9 & -53.7 & $<0.001$ \\
\hline Nestlé & 277 & 313 & 14 & 10 & 0.88 & -10 & -13 & 0.36 & -0.3 & -9.3 & 0.52 & 0.0 & -7.4 & 0.62 & 0.0 & 0.0 & 0.76 & 0.5 & 6.4 & 0.94 \\
\hline Ocean Spray & 32 & 38 & -8 & -15 & 0.15 & -4 & -28.6 & 0.27 & 0.0 & $\mathrm{~N} / \mathrm{A}^{4}$ & 0.37 & 0.0 & $\mathrm{~N} / \mathrm{A}^{4}$ & - & -2.4 & -18.2 & 0.11 & -2.0 & -15.6 & 0.14 \\
\hline Parmalat & 72 & 120 & 145 & 129 & 0.10 & 278 & 463 & 0.49 & 8.0 & 400.0 & 0.01 & 0.5 & $\begin{array}{c}2531 \\
6\end{array}$ & 0.001 & -1.6 & -33.3 & 0.30 & 0.0 & $\mathrm{~N} / \mathrm{A}^{4}$ & 0.19 \\
\hline PepsiCo & 267 & 340 & -27 & -7 & 0.055 & -21 & -5 & 0.18 & -0.4 & -22.0 & 0.14 & 0.0 & $\mathrm{~N} / \mathrm{A}^{4}$ & 0.67 & -0.7 & -12.5 & 0.55 & 0.3 & 8.3 & 0.73 \\
\hline Saputo & 78 & 95 & 0 & 0 & 0.12 & -99 & -33 & 0.85 & 2.0 & 32.1 & 0.03 & 0.3 & 455.6 & 0.009 & -5.8 & -54.7 & $<0.001$ & -6.3 & -100.0 & $<0.001$ \\
\hline Sobeys & 1248 & 1633 & 15 & 7 & 0.20 & 22 & 8 & 0.93 & 0.3 & 33.3 & 0.01 & 0.0 & $\mathrm{~N} / \mathrm{A}^{4}$ & 0.04 & -0.8 & -16.7 & 0.44 & -1.0 & -53.1 & 0.007 \\
\hline Sun-Rype & 40 & 36 & -1 & -2 & 0.39 & 16 & 146 & 0.70 & 0.0 & $\mathrm{~N} / \mathrm{A}^{4}$ & 0.36 & 0.0 & $\mathrm{~N} / \mathrm{A}^{4}$ & - & -0.4 & -3.2 & 0.62 & -0.4 & -3.2 & 0.56 \\
\hline Unilever & 200 & 217 & -6 & -5 & 0.37 & -24 & -9 & 0.10 & -0.4 & -50.3 & 0.11 & 0.0 & $\mathrm{~N} / \mathrm{A}^{4}$ & 0.56 & -0.6 & -18.8 & 0.53 & -0.4 & -35.9 & 0.86 \\
\hline
\end{tabular}

\begin{abstract}
${ }^{1}$ Median nutrient values in each company's products in 2013 are presented overall and by food category in Supplementary Table 4 (Additional File 1); 2017 values have been published elsewhere [3]. ${ }^{2}$ Percentage change was calculated by dividing the difference in median calorie or nutrient contents between 2013 and 2017 by the median amount of calories or the nutrient in 2013, multiplied by 100. Percentage change colour scale was adapted from: Neal B, Sacks G, Shahid M, Taylor F, Huffman M. FoodSwitch: State of the Food Supply (April 2019) 2019. Available from: https://www.georgeinstitute.org/sites/default/files/food_supply_report. pdf. ${ }^{3}$ Results of Mann-Whitney U tests; $p$-values $<0.05$ were considered statistically significant (shown in boldface). A dash (-) indicates that a $p$-value could not be calculated for companies that had $0 \mathrm{~g}$ of that nutrient in all products offered in both 2013 and $2017 .{ }^{4} \mathrm{~N} / \mathrm{A}$ indicates that percentage change could not be determined when the median nutrient value per $100 \mathrm{~g}$ (or mL) in 2013 was $0 \mathrm{~g} .{ }^{5} \mathrm{In} 2013$, Kraft Foods and Heinz were two separate companies prior to merging in 2015 and forming The Kraft Heinz Company. However, to enable examination of changes in the nutritional quality of the company's products over time - and because Kraft Heinz was assessed as one company using the FCR scoring tool - Kraft and Heinz were treated as a single company in 2013, as was done in similar research conducted on the Australian market [24]
\end{abstract}

lower HSRs $(\exp (\beta)=0.892, p<0.001)$. There was no significant difference in the change in HSRs from 2013 to 2017 between products offered by companies with higher versus lower FCR total scores $(p=0.52)$.

\section{Calories per $100 \mathrm{~g}$ (or $\mathrm{mL}$ ) and FCR energy/portion size scores}

Calories per $100 \mathrm{~g}$ (or $\mathrm{mL}$ ) were lower in 2017 than 2013 $(\exp (\beta)=0.990, p<0.001)$. Differences in calories between 2013 and 2017 were larger among products of companies with higher FCR scores compared to the products of lower-scoring companies $(\exp (\beta)=0.994, p=0.001)$. However, it was unclear whether higher FCR scores were associated with larger increases or decreases in calories since the association was not significant $(p=0.08)$.

\section{Sodium per $100 \mathrm{~g}$ (or $\mathrm{mL}$ ) and $\mathrm{FCR}$ sodium scores}

Sodium contents per $100 \mathrm{~g}$ (or $\mathrm{mL}$ ) were lower in 2017 than $2013(\exp (\beta)=0.945, p<0.001)$. There was no significant association between FCR sodium scores and sodium contents $(p=0.56)$. There was no significant difference in the change in sodium contents from 2013 to 2017 between products offered by companies with higher versus lower FCR total scores $(p=0.09)$.

\section{Saturated fat per $100 \mathrm{~g}$ (or $\mathrm{mL}$ ) and FCR saturated fat scores}

Saturated fat contents per $100 \mathrm{~g}$ (or $\mathrm{mL}$ ) were higher in 2017 than $2013(\exp (\beta)=1.028, p=0.006)$. There was no significant association between FCR saturated fat scores and saturated fat contents $(p=0.23)$. Differences in saturated fat contents between 2013 and 2017 were smaller among products of companies with higher FCR scores for saturated fat compared to those of companies with lower scores $(\exp (\beta)=0.961, p=0.001)$.

\section{Trans fat per $100 \mathrm{~g}$ (or $\mathrm{mL}$ ) and FCR trans fat scores}

Trans fat contents per $100 \mathrm{~g}$ (or $\mathrm{mL}$ ) were lower in 2017 than $2013(\exp (\beta)=0.963, p<0.001)$. Differences 
Table 5 Median absolute and percentage changes in the calorie, sodium, saturated fat, trans fat, total sugars and free sugars contents per $100 \mathrm{~g}$ (or $\mathrm{mL}$ ) for products offered by the sampled companies that were matched between 2013 and 2017.1.2

\begin{tabular}{|c|c|c|c|c|c|c|c|c|c|c|c|c|c|c|c|c|c|c|c|}
\hline \multirow[b]{2}{*}{ Company } & \multirow[b]{2}{*}{$\mathbf{n}$} & \multicolumn{3}{|c|}{ Calories (kcal) } & \multicolumn{3}{|c|}{ Sodium (mg) } & \multicolumn{3}{|c|}{ Saturated fat (g) } & \multicolumn{3}{|c|}{ Trans fat (g) } & \multicolumn{3}{|c|}{ Total sugars (g) } & \multicolumn{3}{|c|}{ Free sugars (g) } \\
\hline & & Abs. $\Delta$ & $\% \Delta$ & $\begin{array}{c}\text { p- } \\
\text { value }^{3}\end{array}$ & Abs. $\Delta$ & $\% \Delta$ & $\begin{array}{c}\text { p- } \\
\text { value }^{3}\end{array}$ & Abs. $\Delta$ & $\% \Delta$ & $\begin{array}{c}\text { p- } \\
\text { value }^{3}\end{array}$ & Abs. $\Delta$ & $\% \Delta$ & $\begin{array}{c}\text { p- } \\
\text { value }^{3}\end{array}$ & Abs. $\Delta$ & $\% \Delta$ & $\begin{array}{c}\text { p- } \\
\text { value }^{3}\end{array}$ & Abs. $\Delta$ & $\% \Delta$ & $\begin{array}{c}\text { p- } \\
\text { value }^{3}\end{array}$ \\
\hline A. Lassonde & 35 & 0 & 0 & 1.00 & -2 & -8 & 0.001 & 0.0 & $\mathrm{~N} / \mathrm{A}^{4}$ & $\mathrm{~N} / \mathrm{A}^{4}$ & 0.0 & $\mathrm{~N} / \mathrm{A}^{4}$ & $\mathrm{~N} / \mathrm{A}^{4}$ & 0.0 & 0.0 & 0.01 & 0.0 & 0.0 & 0.01 \\
\hline Agropur & 53 & 0 & 0 & 0.01 & 0 & 0 & 0.98 & 0.0 & 0.0 & 0.08 & 0.0 & 0.0 & 0.09 & 0.0 & 0.0 & 0.003 & 0.0 & -9.0 & $<0.001$ \\
\hline Campbell Soup & 116 & 0 & 0 & 0.84 & 0 & 0 & $<0.001$ & 0.0 & 0.0 & 0.03 & 0.0 & 0.0 & 0.77 & 0.0 & 0.0 & 0.40 & 0.0 & -2.0 & 0.06 \\
\hline Canada Bread & 54 & 0 & 0 & 0.02 & 0 & 0 & 0.07 & 0.0 & 0.0 & 0.43 & 0.0 & 0.0 & 0.36 & 0.0 & 0.0 & 0.03 & 0.5 & 11.9 & $<0.001$ \\
\hline Canada Dry Mott's & 40 & 0 & 0 & 0.62 & 0 & 0 & 0.97 & 0.0 & $\mathrm{~N} / \mathrm{A}^{4}$ & $\mathrm{~N} / \mathrm{A}^{4}$ & 0.0 & $\mathrm{~N} / \mathrm{A}^{4}$ & $\mathrm{~N} / \mathrm{A}^{4}$ & 0.0 & 0.0 & 0.36 & 0.0 & -0.3 & 0.07 \\
\hline Coca-Cola & 68 & 0 & 0 & 0.29 & 0 & 0 & 0.03 & 0.0 & $\mathrm{~N} / \mathrm{A}^{4}$ & $\mathrm{~N} / \mathrm{A}^{4}$ & 0.0 & $\mathrm{~N} / \mathrm{A}^{4}$ & $\mathrm{~N} / \mathrm{A}^{4}$ & 0.0 & 0.0 & 1.00 & 0.0 & 0.0 & 1.00 \\
\hline Danone & 37 & 0 & 0 & 0.02 & 9 & 19 & $<0.001$ & 0.0 & 0.0 & 1.00 & 0.0 & 0.0 & 0.001 & 0.0 & 0.0 & 1.00 & -0.3 & -3.2 & 0.07 \\
\hline General Mills & 194 & 0 & 0 & 0.01 & 0 & 0 & $<0.001$ & 0.0 & 0.0 & 0.002 & 0.0 & -90.0 & $<0.001$ & 0.0 & 0.0 & 0.04 & 0.0 & -0.1 & 0.01 \\
\hline George Weston & 65 & 0 & 0 & 0.006 & 0 & 0 & 0.26 & 0.0 & 0.0 & 0.001 & 0.0 & 0.0 & 1.00 & 0.0 & 0.0 & 0.68 & 0.4 & 12.7 & $<0.001$ \\
\hline Kellogg & 84 & 0 & 0 & 0.01 & 0 & 0 & $<0.001$ & 0.0 & 0.0 & 0.12 & 0.0 & -100.0 & 0.55 & 0.0 & 0.0 & 0.71 & 0.0 & 0.2 & 0.52 \\
\hline Kraft Heinz ${ }^{5}$ & 292 & 0 & 0 & 0.003 & 0 & 0 & $<0.001$ & 0.0 & 0.0 & $<0.001$ & 0.0 & 0.0 & 0.04 & 0.0 & 0.0 & 0.59 & 0.0 & 0.0 & 0.40 \\
\hline Loblaw & 1479 & 0 & 0 & $<0.001$ & 0 & 0 & $<0.001$ & 0.0 & 0.0 & 0.84 & 0.0 & 0.0 & 0.45 & 0.0 & 0.0 & 0.34 & 0.0 & 0.0 & $<0.001$ \\
\hline Maple Leaf Foods & 90 & 0 & 0 & 0.09 & 0 & 0 & $<0.001$ & 0.0 & 0.0 & 0.99 & 0.0 & 0.0 & 0.33 & 0.0 & 0.0 & 0.53 & 0.0 & -0.1 & 0.24 \\
\hline Mondelēz & 108 & 0 & 0 & 0.03 & -21 & -4 & $<0.001$ & -0.4 & -11.1 & $<0.001$ & 0.0 & -11.6 & 0.001 & 0.0 & 0.0 & 0.18 & 0.0 & 0.0 & 0.79 \\
\hline Nestlé & 158 & 0 & 0 & $<0.001$ & 0 & 0 & 0.005 & 0.0 & 0.0 & $<0.001$ & 0.0 & 0.0 & 0.02 & 0.0 & 0.0 & 0.004 & -0.2 & -3.1 & $<0.001$ \\
\hline Ocean Spray & 25 & 0 & 0 & 0.003 & 0 & 0 & 0.04 & 0.0 & $\mathrm{~N} / \mathrm{A}^{4}$ & $\mathrm{~N} / \mathrm{A}^{4}$ & 0.0 & $\mathrm{~N} / \mathrm{A}^{4}$ & $\mathrm{~N} / \mathrm{A}^{4}$ & 0.0 & 0.0 & 0.70 & 0.0 & 0.0 & 0.70 \\
\hline Parmalat & 41 & 0 & 0 & 0.22 & 0 & 0 & 0.38 & 0.0 & 0.0 & 0.35 & 0.0 & 0.0 & 0.11 & 0.0 & 0.0 & 0.48 & 0.0 & -3.9 & 0.29 \\
\hline PepsiCo & 199 & 0 & 0 & 0.07 & 0 & 0 & 0.28 & 0.0 & 0.0 & 0.50 & 0.0 & 0.0 & 1.00 & 0.0 & 0.0 & 0.88 & 0.0 & 0.0 & 0.12 \\
\hline Saputo & 30 & 0 & 0 & 0.06 & 0 & 0 & 0.41 & 0.0 & 0.0 & 0.45 & 0.0 & 0.0 & 0.08 & 0.0 & 0.0 & 1.00 & 0.0 & -0.6 & 0.62 \\
\hline Sobeys & 754 & 0 & 0 & 0.04 & 0 & 0 & $<0.001$ & 0.0 & 0.0 & 0.89 & 0.0 & 0.0 & 0.53 & 0.0 & 0.0 & 0.04 & 0.0 & 0.0 & 0.92 \\
\hline Sun-Rype & 19 & 0 & 0 & 0.09 & 0 & 0 & 0.17 & 0.0 & $\mathrm{~N} / \mathrm{A}^{4}$ & $\mathrm{~N} / \mathrm{A}^{4}$ & 0.0 & $\mathrm{~N} / \mathrm{A}^{4}$ & $\mathrm{~N} / \mathrm{A}^{4}$ & 0.0 & 0.0 & 0.09 & 0.0 & 0.0 & 0.02 \\
\hline Unilever & 133 & 0 & 0 & 0.01 & -4 & -2 & $<0.001$ & 0.0 & 0.0 & 0.003 & 0.0 & -33.3 & $<0.001$ & 0.0 & 0.0 & 0.37 & 0.0 & -5.9 & 0.07 \\
\hline
\end{tabular}

${ }^{1}$ Absolute and percentage changes were calculated based on the 2013 and 2017 cal/nutrient amount of each matched product (by dividing the difference in 2013 and $2017 \mathrm{cal} /$ nutrient amount by the $2013 \mathrm{cal} /$ nutrient amount, multiplied by 100), and then averaged across all products to generate median absolute and percentage changes. Percentage change colour scale was adapted from: Neal B, Sacks G, Shahid M, Taylor F, Huffman M. FoodSwitch: State of the Food Supply (April 2019) 2019. Available from: https://www.georgeinstitute.org/sites/default/files/food_supply_report.pdf. ${ }^{2}$ Individual products offered by the sampled companies in both 2013 and 2017 were matched either by barcode or manually by identifying products with identical brand and product names, and the same or similar Nutrition Facts tables, ingredients lists and product packaging. ${ }^{3}$ Results of Wilcoxon signed-rank tests; $p$-values $<0.05$ were considered statistically significant (shown in boldface). ${ }^{4} \mathrm{~N} / \mathrm{A}$ indicates that percentage change and $\mathrm{p}$-values could not be calculated for companies whose matched products all contained $0 \mathrm{~g}$ of the nutrient in both 2013 and 2017. ${ }^{5}$ In 2013, Kraft Foods and Heinz were two separate companies prior to merging in 2015 and forming The Kraft Heinz Company. However, to enable examination of changes in the nutritional quality of the company's products over time - and because Kraft Heinz was assessed as one company using the FCR scoring tool - Kraft and Heinz were treated as a single company in 2013, as was done in similar research conducted on the Australian market [24]

in trans fat contents between 2013 and 2017 were larger among products of companies with higher FCR scores, compared to products of lower-scoring companies $(\exp (\beta)=0.949, p<0.001)$. However, it was unclear whether higher FCR scores were associated with larger increases or decreases in trans fat since the association was not significant $(p=0.07)$.

\section{Total sugars per $100 \mathrm{~g}$ (or $\mathrm{mL}$ ) and FCR sugars scores}

Total sugars contents per $100 \mathrm{~g}$ (or $\mathrm{mL}$ ) were not significantly different between 2013 and $2017(p=0.29)$. Higher FCR scores for sugars were associated with higher total sugars contents $(\exp (\beta)=1.545, \mathrm{p}<0.001)$. There was no significant difference in the change in total sugars contents from 2013 to 2017 between products offered by companies with higher versus lower FCR total scores $(p=0.07)$.

\section{Free sugars per $100 \mathrm{~g}$ (or $\mathrm{mL}$ ) and FCR sugars scores}

Free sugars contents per $100 \mathrm{~g}$ (or $\mathrm{mL}$ ) were lower in 2017 than $2013(\exp (\beta)=0.986, p=0.009)$. Higher FCR sugars scores were associated with higher free sugars contents $(\exp (\beta)=1.109, \mathrm{p}<0.001)$. There was no significant difference in the change in free sugars contents from 2013 to 2017 between products offered by companies with higher versus lower FCR total scores $(p=0.06)$.

\section{Discussion}

While some of Canada's leading food and beverage companies have recently improved the healthfulness of their products, most companies' product portfolios did not change significantly or were less healthy in 2017 than 2013. Higher FCR scores, which identify companies with stronger commitments to improving product healthfulness, were not associated with greater improvements in HSRs, calories or any of the nutrients/components 


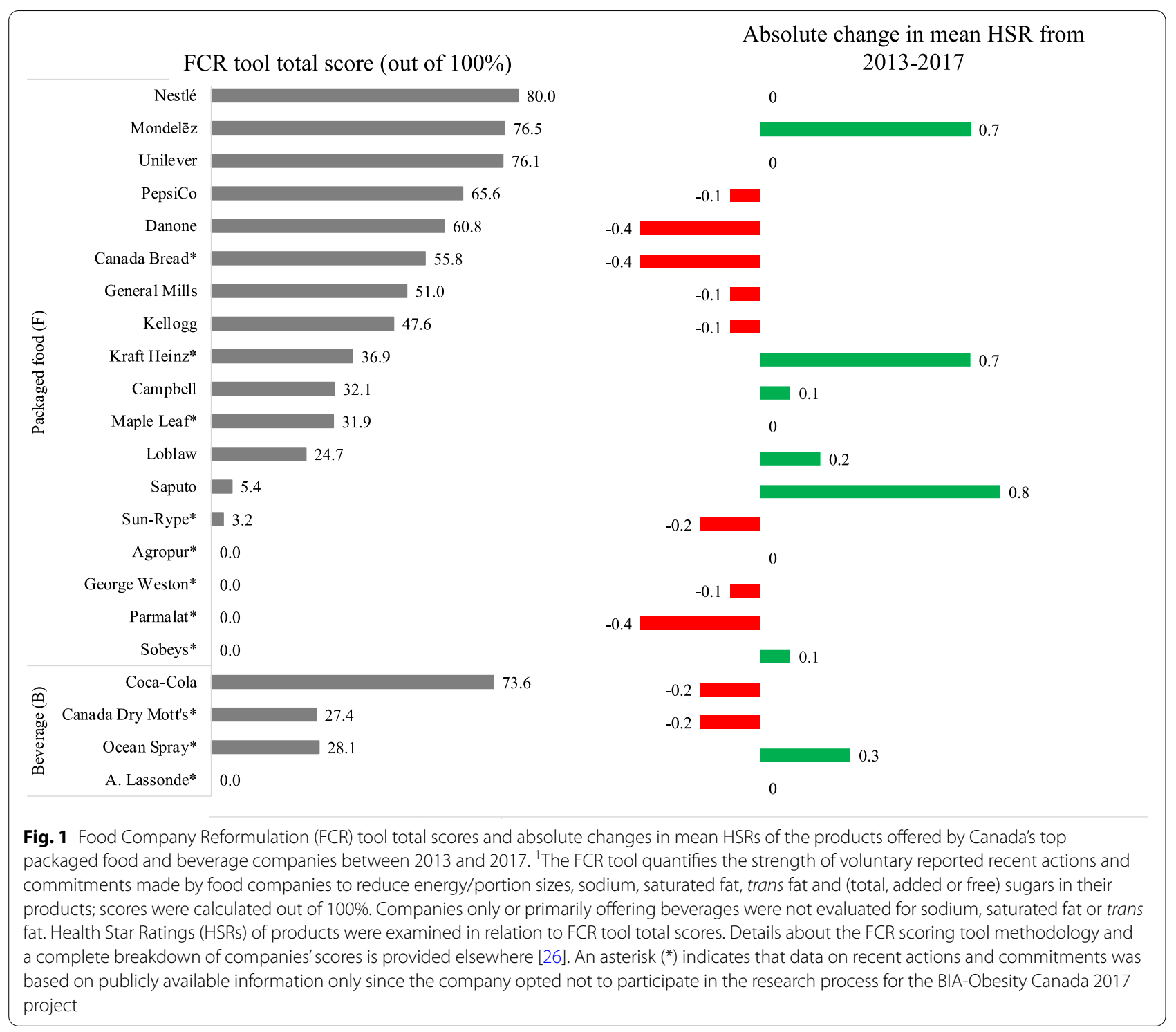

examined. Additionally, higher FCR scores were associated with lower HSRs (i.e., less healthy), and higher total and free sugars contents, while no relationship was observed between FCR scores and calories, sodium, saturated fat or trans fat contents. Most companies reported weak recent actions or commitments to make their products healthier, or none at all, as demonstrated by the low FCR tool scores [26]. Even among companies reporting stronger recent actions and commitments concerning product (re) formulation (i.e., higher FCR scores), larger improvements in the healthfulness of their products were not seen, suggesting a considerable degree of "over-reporting" by companies. For example, while Nestle had the highest FCR scores in total and for each nutrient/component except energy/portion sizes, there was no significant change in the mean HSRs or median calories, sodium, saturated fat, trans fat or total and free sugars contents of their products from 2013 to 2017. In combination, these results suggest that most companies' voluntary reformulation initiatives often do not result in healthier packaged foods and beverages.

Previous studies have identified important weaknesses in the voluntary actions and commitments of packaged food and beverage companies concerning product (re) formulation that limit their potential to significantly improve the healthfulness of their products or the diet quality of consumers [20-22, 24-26, 49]. Several companies in this sample had reduced or committed to reducing levels of one or more nutrients/components of concern in their products [26]. Many of these recent actions and 


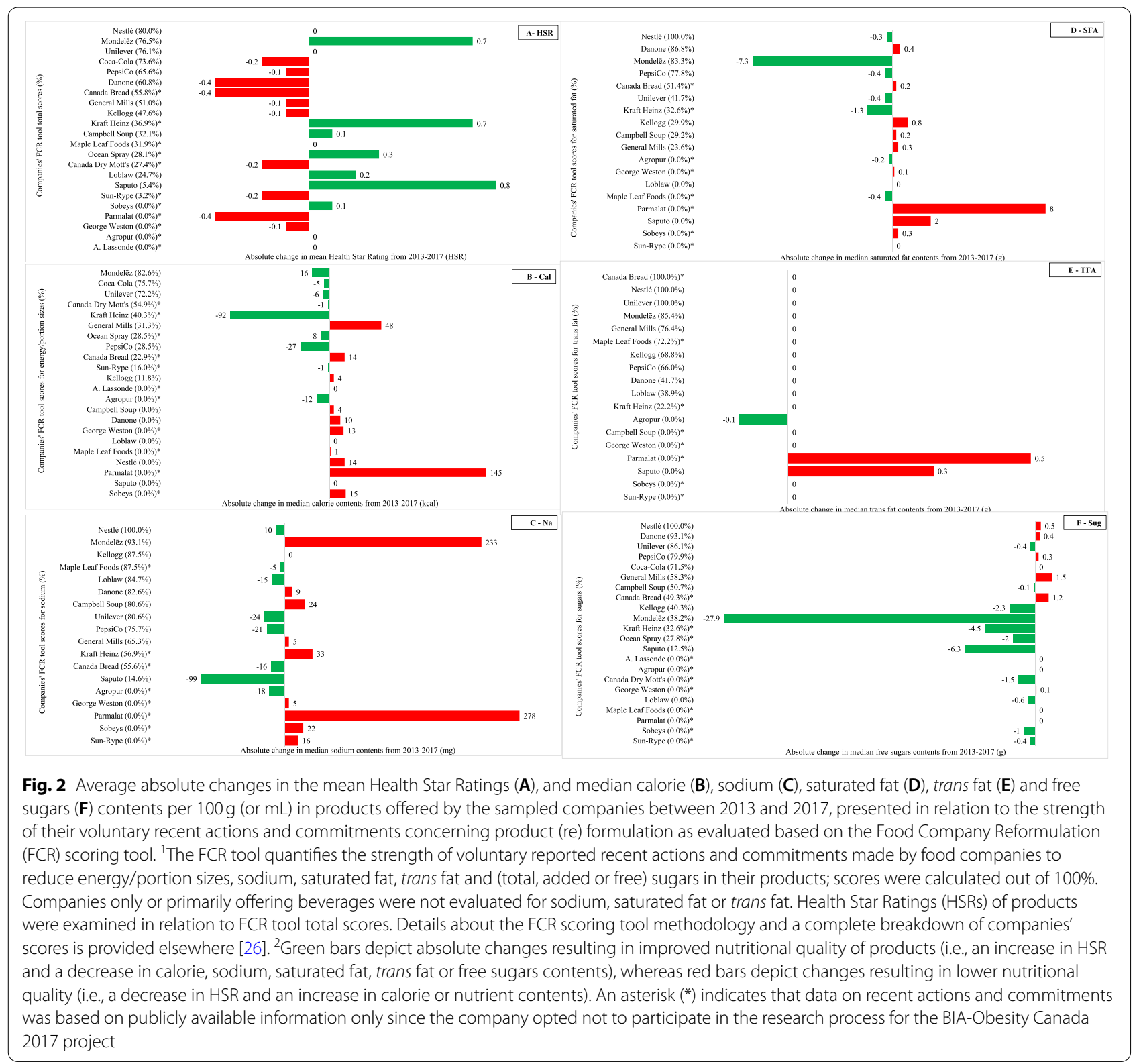

commitments were, however, poorly defined, applicable to few food categories, affected a small (or undisclosed) proportion of the company's sales, not expressed in relation to government or WHO reformulation targets and recommendations, applied inconsistently across national markets, and progress in meeting reformulation targets was not publicly and regularly reported [26]. Previous research suggests that food companies' voluntary pledges are often little more than a public relations or a corporate social responsibility strategy intended to convince consumers, policymakers and shareholders that the company prioritizes nutrition and health, while also helping to circumvent government regulations concerning the nutritional quality of the packaged food supply [50-52]. Findings from this study clearly support this notion and demonstrate that many of Canada's top food companies are failing to substantially ameliorate the healthfulness of their products, irrespective of whether they have made commitments to do so or not.

Many countries have introduced voluntary or mandatory nutrient reduction targets, with sodium and trans fat reformulation policies being the most common $[53,54]$. In Canada, the federal government published voluntary sodium reduction targets for each food category in 2012 [55], and banned partially hydrogenated oils (PHOs) in packaged and restaurant foods in 2018 [56], following 
Table 6 Results of generalized estimating equations examining Health Star Ratings (HSRs), and calories, sodium, saturated fat, trans fat, total sugars and free sugars per $100 \mathrm{~g}(\mathrm{or} \mathrm{mL}$ ) in products offered by the top packaged food and beverage companies in Canada in relation to the year of collection (2013 or 2017), Food Company Reformulation (FCR) tool total scores or sub-scores for energy/portion sizes, sodium, saturated fat, trans fat or sugars, adjusted for food category ${ }^{a, b}, c, d$

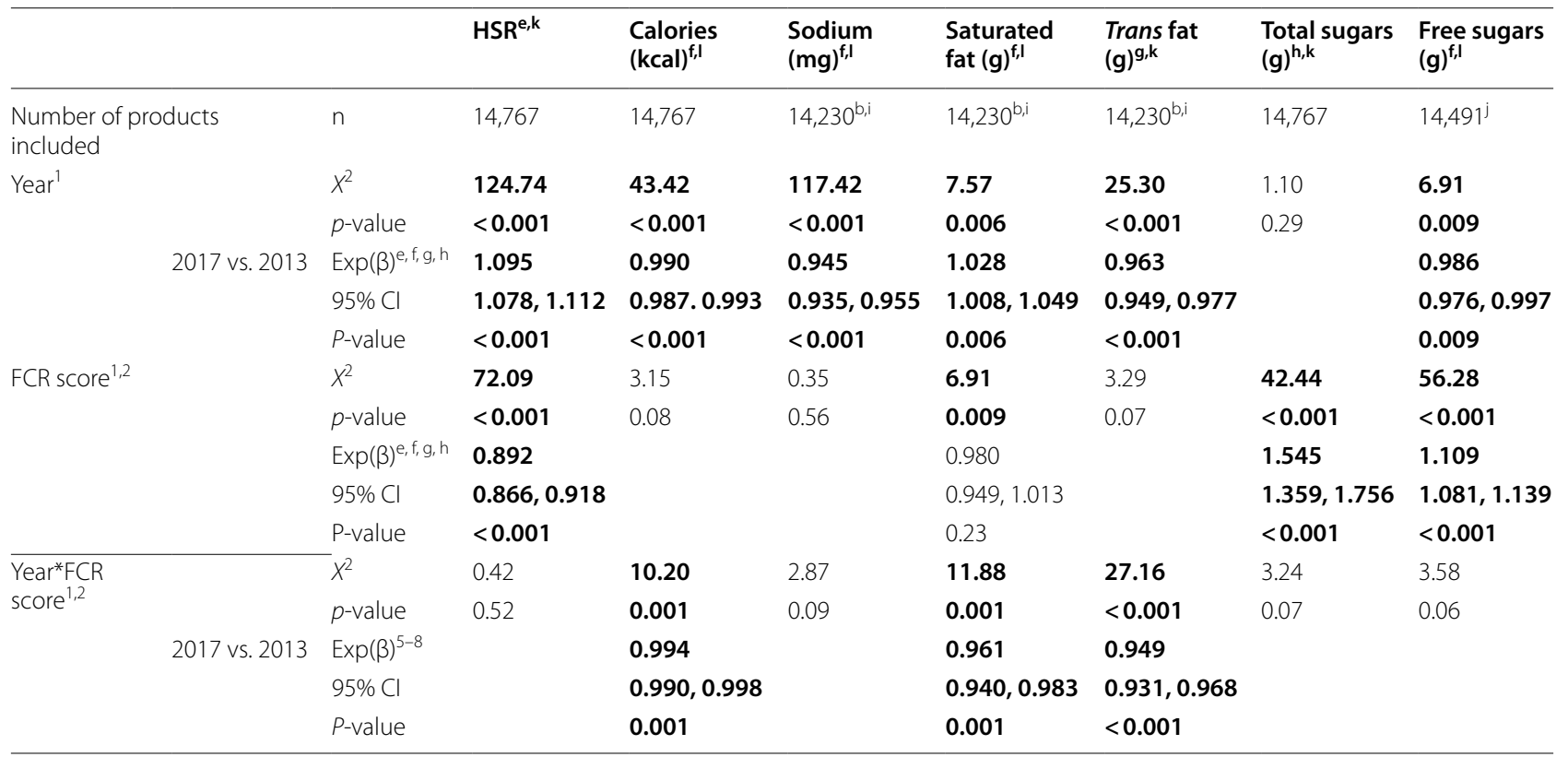

${ }^{a}$ The generalized estimating equation analyses tested whether higher FCR tool scores (entered as a standardized continuous variable) were associated with greater increases in HSRs (i.e., healthier) or decreases in calories, sodium, saturated fat, trans fat, total sugars or free sugars per $100 \mathrm{~g}$ (or $\mathrm{mL}$ ) between $2013 \mathrm{and} 2017$. Coefficients for the "year" variable measured whether HSRs, calories or nutrient levels (per $100 \mathrm{~g} \mathrm{or} \mathrm{mL)} \mathrm{tended} \mathrm{to} \mathrm{be} \mathrm{higher} \mathrm{or} \mathrm{lower} \mathrm{in} 2017$ compared to 2013 . The "FCR score" variable coefficients measured whether there was an association between FCR scores and HSRs, calories or nutrient levels in products (per $100 \mathrm{~g}$ or $\mathrm{mL}$ ). The "year*FCR score" variable examined whether the change in HSRs or calorie/nutrient density over time differed between products offered by companies with higher versus lower FCR tool scores. An association between higher FCR scores and greater improvements in nutritional quality between 2013 and 2017 would be suggested if all three of the following results were observed and statistically significant $(p<0.05): 1)$ calorie or nutrient amounts were lower in 2017 than 2013 (and HSRs were higher in 2017 than 2013); 2) FCR scores were negatively associated with calorie/nutrient amounts (and positively associated with HSRs); and 3) the "year*FCR score" interaction term variable was negative for calorie/nutrient outcome models (i.e., exp. $(\beta)<1$ ) and positive for the HSR outcome model (exp $(\beta)>1$; indicating a greater change in nutritional quality in higher-scoring companies' products between 2013 and 2017). ${ }^{b}$ The FCR tool quantifies the strength of voluntary recent actions and commitments reported by food companies to reduce energy/portion sizes, sodium, saturated fat, trans fat and (total, added or free) sugars in their products; scores were calculated out of $100 \%$. Companies only or primarily offering beverages were not evaluated for sodium, saturated fat or trans fat. HSRs of products were examined in relation to FCR tool total scores. Details about the FCR scoring tool methodology and a complete breakdown of companies'scores is provided elsewhere [26]. 'Food categories are defined in Health Canada's Table of Reference Amounts for Food [39]. 'Boldface values indicate statistically significant tests of model effects and pairwise comparisons; $\mathrm{p}$-values $<0.05$ were considered significant. For all contrasts, the reference category is listed second. Pairwise contrasts are not shown for variables that did not have a significant overall effect. ${ }^{~}$ Based on a model with an inverse gaussian distribution and an identity link. ${ }^{\mathrm{f}}$ Based on a model with a Tweedie distribution and a logarithm link. ${ }^{9}$ Based on a model with a normal distribution and an identity link. ${ }^{\mathrm{h}}$ Based on a model with a Tweedie distribution and an identity link. 'Products offered by beverage companies did not receive FCR tool scores for sodium, saturated fat or sugars, resulting in the exclusion of 537 products and a smaller sample size for these models. ${ }^{j}$ Model excluded 276 products for which free sugars could not be estimated in the absence of an ingredients list. ${ }^{\mathrm{k}} \operatorname{Exp}(\beta)$ is the expected change in the mean of the dependent variable for each 1-unit change in a covariate. ${ }^{\prime} \mathrm{A} 1$-unit change in a covariate multiplies the mean value of the dependent variable by exp.( $\beta$ )

the release of voluntary targets in 2006 [57]. An assessment conducted by Health Canada in 2017 found that, on average, products in most food categories failed to meet their sodium targets, with many categories showing an increase in sodium since 2012 [31]. Our findings are consistent with these results, as only two companies significantly reduced the median sodium content of their product portfolios and three companies increased average sodium levels in their products from 2013 to 2017. In light of this lack of improvement in sodium levels, Health Canada recently released updated voluntary sodium reduction targets for 2020-2025 [58]. Although there was relatively little change in the trans fat content of the product portfolios of most companies in this study, nearly all had a median trans fat content of $0 \mathrm{~g}$ in 2013 and 2017, suggesting that they were already on track to comply with Health Canada's prohibition on adding PHOs to their Canadian products by September 2018 [56, 59]. Nonetheless, in the absence of government-endorsed reformulation targets for other nutrients in Canada, the nutritional quality of the packaged food supply is largely reliant on the voluntary actions and commitments of food and beverage companies to offer healthier products. Establishing stronger voluntary nutrient reduction 
targets and, more importantly, ensuring that companies actually make meaningful improvements to the nutritional quality of their products, will therefore be critical in reducing intakes of nutrients/components of concern by Canadians.

Food companies can make their product portfolios healthier through reformulation of existing products, and by acquiring or discontinuing healthier and less healthy products, respectively [24, 28]. For several of the food categories examined, there were substantial differences between companies in terms of the change in nutrient composition that occurred from 2013 to 2017 (e.g., sauces, bakery products, dairy products, fats/oils; Supplementary Table 2, Additional File 1), demonstrating that improving the healthfulness of companies' product offerings is possible. There was also considerable turnover in the Canadian product portfolios of these companies between 2013 and 2017, with less than two-thirds of the total products collected in 2013 being sold in 2017 . There were considerably greater changes in the HSRs, calories and nutrient amounts of products that were newly introduced, discontinued, and acquired from or sold to unsampled companies between 2013 and 2017 than in those of matched products. While there were changes in median calorie and nutrient amounts in several companies' product portfolios, median changes in calories and nutrients for matched products were zero for most companies. These differences indicate that most of the observed change in the healthfulness of companies' product portfolios is likely due to changes to a company's product mix (e.g., introducing or acquiring new healthier products, or discontinuing or selling off less healthy products), rather than actual reformulation of products. The former scenario may not necessarily improve the healthfulness of Canada's overall packaged food supply; although, the acquisition of healthier products by top food companies with the most influence on the Canadian market could help ensure that these products are more accessible, available and marketed to consumers over less healthy alternatives. Nonetheless, Health Canada's 2017 sodium monitoring data showed very few improvements overall in the Canadian packaged food supply when data were sales-weighted [31].

A strength of this study is its use of a large and highly representative sample of major packaged food and beverage companies and their Canadian product portfolios. Changes in companies' products were assessed in terms of both a nutrient profile model and several individual nutrients/components, accounting for inherent differences in the nature of companies' product portfolios. This work was novel in its examination of the nutritional composition of matched, newly acquired/ introduced and discontinued products, which are often neglected in cross-sectional analyses of packaged food supplies. A limitation of this study is that it cannot directly assess companies' compliance with their voluntary product (re) formulation recent actions and commitments. A compliance assessment was not feasible given the limited information made public by companies concerning their product (re) formulation actions and commitments, and since FLIP may not include all products offered by these companies in Canada in 2013 and 2017, given that data were only collected from an outlet of 3-4 top grocery retailers at one point in time [26]. Although the FCR scoring tool comprehensively evaluated and quantified the strength of companies' reformulation actions and commitments, effectively differentiating between companies based on their performance in this area, it also has several weaknesses, which have been described in detail elsewhere [26]. In addition, since the data were not sales-weighted, it is unclear how the healthfulness of products constituting larger proportions of companies' Canadian sales may have changed in recent years. Lastly, the policy and food supply data used in this study are from 2017 or earlier; companies may have taken further actions to improve the healthfulness of their products since then.

\section{Conclusions}

While some top packaged food and beverage companies in Canada made their products healthier between 2013 and 2017, many companies' product portfolios were unchanged or became significantly less healthy during this period. The product portfolios of companies reporting stronger voluntary recent actions and/ or commitments concerning product (re) formulation did not undergo greater improvement in HSRs, calories or nutrients/components of public health concern, and their products were not significantly healthier. These findings suggest that company commitments to improve the nutritional quality of the packaged food supply do not signify improvements in the nutritional profile of their products, demonstrating a need for mandatory government interventions to improve the nutritional quality of the Canadian packaged food supply.

\footnotetext{
Abbreviations

BIA-Obesity: Business Impact Assessment - Obesity and population-level nutrition; FCR: Food Company Reformulation; FLIP: Food Label Information Program; FVNL: Fruit; : vegetable; : nut and legume; GEE: Generalized estimating equation; HSR: Health Star Rating; NCD: Non-communicable disease; NFt: Nutrition Facts table; NP: Nutrient profile; TRA: Table of Reference Amounts for Food; SMART: Specific, measurable, attainable, relevant and timely; WHO: World Health Organization.
} 


\section{Supplementary Information}

The online version contains supplementary material available at https://doi. org/10.1186/s12889-022-12683-2.

Additional file 1: Supplementary Table 1. Weighted Food Company Reformulation tool scores of the top packaged food and beverage companies in Canada. Supplementary Table 2. Absolute and percentage changes in mean Health Star Ratings and median calories, sodium, saturated fat, trans fat, total sugars and free sugars per $100 \mathrm{~g}(\mathrm{or} \mathrm{mL}$ ) from 2013 to 2017 in the total portfolio of products offered by each company, presented by food category. Supplementary Table 3. Mean and median absolute and percentage changes in Health Star Ratings, calories, sodium, saturated fat, trans fat, total sugars and free sugars per $100 \mathrm{~g}(\mathrm{or} \mathrm{mL})$ in products offered by each company that were matched between 2013 and 2017, presented by food category. Supplementary Table 4. Mean Health Star Ratings and median amounts of calories, sodium, saturated fat, trans fat, total sugars and free sugars per $100 \mathrm{~g}$ (or $\mathrm{mL}$ ) in products offered by each company in 2013, presented overall and by food category. Supplementary Fig. 1. The approach used to derive the sample of products examined in this study.

Additional file 2:. Evaluating the Validity, Internal Consistency and Interrater Reliability of the Food Company Reformulation (FCR) Scoring Tool.

\section{Acknowledgements}

The authors thank Dr. Gary Sacks, Ella Robinson, Dr. Sally Mackay and Dr. Leanne Young for their valuable contributions to the development of the Food Company Reformulation scoring tool [26].

\section{Authors' contributions}

The authors' contributions were as follows: LVe, LVa and MRL designed research; LVe, MA, CM, BFA and KD applied HSRs to products in FLIP 2017; MA, BFA, JTB and MEL estimated FVNL points and completed product categorizations that supported the determination of HSRs for products in FLIP 2013; LVe and MA calculated HSRs for products in FLIP 2013; MW and JTB estimated free sugars contents of products; LVe conducted research, analyzed data and wrote the manuscript; MA and MW provided advice/support in data analysis; MRL had primary responsibility for final content. All authors critically reviewed the manuscript and approved its final version.

\section{Funding}

Canadian Institutes of Health Research (CIHR) Frederick Banting and Charles Best Canada Graduate Scholarship Doctoral Award (LVe, CM, BFA); Ontario Graduate Scholarship (LVe, CM); Department of Nutritional Sciences Graduate Student Fellowship (LVe, BFA); Mitacs Elevate Postdoctoral Fellowship (M.A.); CIHR Banting Postdoctoral Fellowship (LVa); ClHR Frederick Banting and Charles Best Canada Graduate Scholarships Mater's Award (CM); University of Toronto Banting and Best Diabetes Centre Graduate Award (MW); Endeavour Research Fellowship (KD); Foundation for High Blood Pressure Research Early Career Research Transition Grant (KD); ClHR Postdoctoral Fellowship (MEL); CIHR Strategic Operating Grants (201103SOK-1 18150; 2016PJT-152979) (MRL); Earle W. McHenry Research Chair unrestricted research grant from the University of Toronto (MRL). The funding bodies had no role in the study design, data collection and analysis, interpretation of results, or writing of the manuscript.

\section{Availability of data and materials}

The datasets generated and/or analysed during the current study are not publicly available but are available from the corresponding author on reasonable request. The Food Label Information Program (FLIP) 2017 database is owned and maintained by Dr. Mary R. L'Abbé (the senior author) and is not publicly available; permission to access this data was granted by Dr. L'Abbé and is open to other researchers for non-commercial uses through research collaborations and data sharing agreements.

\section{Declarations}

Ethics and approval and consent to participate

Given that this research did not involve human (or animal) participants, biological materials or the secondary use of personal information, ethics approval by University of Toronto Research Ethics Board was not required: https://research.utoronto.ca/ethics-human-research/when-do-i-need-humanethics-protocol. This is compliant with the Government of Canada's Tri-Council Policy Statement: Ethical Conduct for Research Involving Humans (Articles 2.1 and 2.2): https://ethics.gc.ca/eng/tcps2-eptc2_2018_chapter2-chapitre2. html\#1. However, ethics approval was obtained for the BIA-Obesity Canada 2017 project from the University of Toronto Research Ethics Board (protocol number: 00033857).

\section{Consent for publication}

Not applicable.

\section{Competing interests}

MA was a Mitacs Elevate Postdoctoral Fellow and was jointly funded by the Government of Canada Mitacs program and Nestlé Research Center from September 2017 to September 2019. Prior coming to the University of Toronto, BFA was a PepsiCo Mexico employee. CM completed a Mitacs graduate student internship placement at Nestlé Canada, funded by the Government of Canada Mitacs program. MRL reports grants from the Retail Council of Canada, Program for Food Safety, Nutrition and Regulatory Affairs at the University of Toronto (with partial funding from Nestlé Canada), and Dairy Farmers of Canada; these grants are unrelated to the submitted work. None of these companies/organizations had any involvement in the present research. The other authors have no conflicts of interest to declare.

\section{Author details}

${ }^{1}$ Department of Nutritional Sciences, Temerty Faculty of Medicine, University of Toronto, 1 King's College Circle, Toronto, Ontario M5S 1A8, Canada. ${ }^{2}$ Centre nutrition, santé et société (NUTRISS), Institut sur la nutrition et les aliments fonctionnels, École de nutrition, Université Laval, Pavillon des Services, 2440 boul. Hochelaga, Québec, Québec G1V 0A6, Canada. ${ }^{3}$ Faculty of Health Science, Ontario Tech University, 2000 Simcoe Street North, Oshawa, ON L1G OC5, Canada. ${ }^{4}$ Nutrition and Dietetics, College of Nursing and Health Sciences, Flinders University, G.P.O. Box 2100, Adelaide, SA 5001, Australia.

Received: 13 July 2021 Accepted: 31 January 2022

Published online: 10 February 2022

\section{References}

1. Neal B, Sacks G, Swinburn B, Vandevijvere S, Dunford E, Snowdon W, et al. Monitoring the levels of important nutrients in the food supply. Obes Rev. 2013;14(Suppl 1):49-58

2. Vergeer L, Veira P, Bernstein JT, Weippert M. L'Abbé MR. the calorie and nutrient density of more- versus less-processed packaged food and beverage products in the Canadian food supply. Nutrients. 2019;11(11).

3. Vergeer L, Vanderlee L, Ahmed M, Franco-Arellano B, Mulligan C, Dickinson $\mathrm{K}$, et al. A comparison of the nutritional quality of products offered by the top packaged food and beverage companies in Canada. BMC Public Health. 2020;20(1):650.

4. Polsky JY, Moubarac J-C, Garriguet D. Consumption of ultra-processed foods in Canada. Health Rep. 2020;21(11):3-15.

5. Nardocci M, Leclerc BS, Louzada ML, Monteiro CA, Batal M, Moubarac JC. Consumption of ultra-processed foods and obesity in Canada. Can J Public Health. 2019;110(1):4-14.

6. Nardocci M, Polsky J, Moubarac JC. How ultra-processed foods affect health in Canada. Report prepared for heart and stroke. Montréal: TRANSNUT, Department of Nutrition. University of Montreal. 2019; https://www. heartandstroke.ca/-/media/pdf-files/canada/media-centre/hs-moubarcstudy-june-27-2019.ashx?rev=8ac040d6d03a41209fc6d8353ed325b3\& hash=81 A02F9268388596BD7089AA9C22419D. Accessed 6 Jan 22.

7. Moubarac J. Ultra-processed foods in Canada: consumption, impact on diet quality and policy implications. Montréal: TRANSNUT, University of Montreal. 2017; https://www.heartandstroke.ca/-/media/pdf-files/ 
canada/media-centre/hs-report-upp-moubarac-dec-5-2017.ashx. Accessed 6 Jan 22.

8. Health Canada. Sodium intake of Canadians in 2017; 2018. https://www canada.ca/en/health-canada/services/publications/food-nutrition/ sodium-intake-canadians-2017.html. Accessed 6 Jan 22.

9. World Health Organization. Global strategy on diet, physical activity and health. Geneva; 2004. https://www.who.int/dietphysicalactivity/strategy/ eb11344/strategy_english_web.pdf. Accessed 21 Jun 2021

10. World Health Organization. Global action plan for the prevention and control of non-communicable diseases 2013-2020. Geneva, Switzerland: World Health Organization; 2013. p. 1-103.

11. Dobbs R, Savers C, Thompson F, Manyika J, Woetzel J, Child P, et al. Overcoming obesity: an initial economic analysis. McKinsey Global Institute. 2014; https://www.mckinsey.com/ /media/mckinsey/business\%20fun ctions/economic\%20studies\%20temp/our\%20insights/how\%20the\% 20world\%20could\%20better\%20fight\%20obesity/mgi_overcoming_ obesity_full_report.ashx. Accessed 6 Jan 22.

12. Federici $C$, Detzel P, Petracca F, Dainelli $L$, Fattore $G$. The impact of food reformulation on nutrient intakes and health, a systematic review of modelling studies. BMC Nutr. 2019;5:2.

13. World Health Organization. 'Best buys' and other recommended interventions for the prevention and control of noncommunicable diseases 2017. https://apps.who.int/iris/bitstream/handle/10665/259232/WHO-NMHNVI-17.9-eng.pdf?sequence=1\&isAllowed=y. Accessed 6 Jan 22.

14. Spiteri M, Soler LG. Food reformulation and nutritional quality of food consumption: an analysis based on households panel data in France. Eur J Clin Nutr. 2018;72(2):228-35.

15. Griffith $R, O^{\prime}$ Connell M, Smith K. The importance of product reformulation versus consumer choice in improving diet quality. Economica. 2017;84(333):34-53.

16. Leroy P, Réquillart V, Soler LG, Enderli G. An assessment of the potential health impacts of food reformulation. Eur J Clin Nutr. 2016;70(6):694-9.

17. Gressier M, Swinburn B, Frost G, Segal AB, Sassi F. What is the impact of food reformulation on individuals' behaviour, nutrient intakes and health status? A systematic review of empirical evidence. Obes Rev. 2021;22(2):e13139.

18. OECD. The heavy burden of obesity: the economics of prevention. Canada: OECD; 2019. https://www.oecd.org/canada/Heavy-burden-ofobesity-Media-country-note-CANADA.pdf. Accessed 6 Jan 22

19. OECD. The heavy burden of obesity: the economics of prevention, OECD health policy studies Paris. OECD Publishing. 2019; https://www.oecdilibrary.org/docserver/67450d67-en.pdf?expires=1599081632\&id=id\&a ccname $=$ guest $\&$ checksum $=$ 2DAD70E0D58B55269FEE45F32CCAD7D0. Accessed 6 Jan 22.

20. Vanderlee L, Vergeer L, Sacks G, Robinson E. L'Abbé M. food and beverage manufacturers in Canada: policies and commitments to improve the food environment: University of Toronto; 2019. http://labbelab.utoronto. ca/bia-obesity-canada-2019/. Accessed 21 Jun 2021.

21. Sacks G, Robinson E, for INFORMAS. Inside our food and beverage manufacturers: assessment of company policies and commitments related to obesity prevention and nutrition, Australia, 2018. Deakin University; https://docs.wixstatic.com/ugd/2e3337_8ec8e664486e4082b80b42028 3597219.pdf. Accessed 21 Jun 2021.

22. Kasture A, Vandevijvere S, Robinson E, Sacks G, Swinburn B. Benchmarking the commitments related to population nutrition and obesity prevention of major food companies in New Zealand. Int J Public Health. 2019;64(8):1147-57.

23. Cetthakrikul N, Phulkerd S, Jaichuen N, Sacks G, Tangcharoensathien V. Assessment of the stated policies of prominent food companies related to obesity and non-communicable disease (NCD) prevention in Thailand. Glob Health. 2019;15(1):12.

24. Access teo Nutrition Foundation. Access to nutrition index: Global Index 2018. https://accesstonutrition.org/index/global-index-2018/. Accessed 21 Jun 2021.

25. Access to Nutrition Foundation. Access to nutrition index: U.S. Spotlight Index 2018. https://www.accesstonutrition.org/us-spotlight-index/usspotlight-index. Accessed 21 Jun 2021.

26. Vergeer L, Vanderlee L, Sacks G, Robinson E, Mackay S, Young L, et al. The development and application of a tool for quantifying the strength of voluntary actions and commitments of Major Canadian food companies to improve the nutritional quality of their products. Current developments in Nutrition. 2020:nzaa151.

27. Access to nutrition initiative. U.K. Product Profile 2019. https://accesstonu trition.org/app/uploads/2020/02/UK-Product-Profile_Full_Report_2019. pdf. Accessed 21 Jun 2021.

28. Neal B, Sacks G, Shahid M, Taylor F, Huffman M. FoodSwitch: state of the food supply (April 2019) 2019. https://www.georgeinstitute.org/sites/ default/files/food_supply_report.pdf. Accessed 21 Jun 2021.

29. Mackay S, Ni Mhurchu C, Swinburn B, Eyles H, Young L, Gontijo de Castro T. State of the food supply: New Zealand 2019. Auckland: The University of Auckland; 2019. https://auckland.figshare.com/articles/State_of_the_ Food_Supply_New_Zealand_2019/9636710. Accessed 21 June 2021

30. Shahid M, Coyle DH, Jones A, Laznik N, Howes K, Taylor F. FoodSwitch: state of the food supply | Australia | August 2020. 2020. https://www. georgeinstitute.org/sites/default/files/foodswitch-state-of-the-food-supply-august-2020.pdf. Accessed 21 Jun 2021.

31. Health Canada. Sodium reduction in processed foods in Canada: an evaluation of Progress toward voluntary targets from 2012 to 2016. 2018. https://www.canada.ca/en/health-canada/services/food-nutrition/legis lation-guidelines/guidance-documents/guidance-food-industry-reduc ing-sodium-processed-foods-progress-report-2017.html. Accessed 21 Jun 2021

32. Public Health England. Sugar reduction: report on progress between 2015 and 2019. 2020. https://www.gov.uk/government/publications/ sugar-reduction-report-on-progress-between-2015-and-2019. Accessed Jun 212021.

33. Sacks G, Swinburn B, Kraak V, Downs S, Walker C, Barquera S, et al. A proposed approach to monitor private-sector policies and practices related to food environments, obesity and non-communicable disease prevention. Obes Rev. 2013;14(Suppl 1):38-48.

34. Packaged food in Canada. Company shares | national - latest owner | historical | \% breakdown. Euromonitor International. 2016.

35. Soft drinks in Canada. Company shares | national - latest owner | historical | \% breakdown. Euromonitor International. 2016.

36. Sacks G, Vanderlee L, Robinson E, Vandevijvere S, Cameron AJ, Ni Mhurchu C, et al. BIA - obesity (business impact assessment - obesity and population-level nutrition): a tool and process to assess food company policies and commitments related to obesity prevention and population nutrition at the national level. Obes Rev. 2019:1-12.

37. Bernstein JT, Schermel A, Mills CM. L'Abbé MR. Total and free sugar content of Canadian prepackaged foods and beverages. Nutrients. 2016;8(9).

38. Franco-Arellano B, Arcand J, Kim MA, Schermel A, L'Abbé MR. Progress towards eliminating industrially produced trans-fatty acids in the Canadian marketplace, 2013-2017. Public Health Nutr. 2020;23(13):2257-67.

39. Health Canada. Nutrition labelling table of reference amounts for food. 2016. https://www.canada.ca/en/health-canada/services/technicaldocuments-labelling-requirements/table-reference-amounts-food.html. Accessed 21 Jun 2021.

40. Guide for industry to the Health Star Rating Calculator (HSRC) 2018. http://healthstarrating.gov.au/internet/healthstarrating/publishing.nsf/ content/E380CCCA07E1E42FCA257DA500196044/\$File/Guide\%20for\% 20Industry\%20to\%20the\%20Health\%20Star\%20Rating\%20Calculator.pdf. Accessed 21 Jun 2021.

41. Poon T, Labonté M, Mulligan C, Ahmed M, Dickinson KM, L'Abbé MR. Comparison of nutrient profiling models for assessing the nutritional quality of foods: a validation study. Br J Nutr. 2018;120(5):567-82.

42. Vergeer L, Ahmed M, Franco-Arellano B, Mulligan C, Dickinson K, Bernstein JT, et al. Methodology for the determination of fruit, vegetable, nut and legume points for food supplies without quantitative ingredient declarations and its application to a large Canadian packaged food and beverage database. Foods. 2020;9(8):1127.

43. Dunford E, Cobcroft M, Thomas M, Wu J. Technical report: alignment of the NSW healthy food provision policy with the health star rating system Sydney, NSW: NSW ministry of. Health. 2015; http://www.health.nsw.gov. au/heal/Publications/health-star-rating-system.pdf. Accesesed 21 Jun 2021.

44. Jones A, Rådholm K, Neal B. Defining 'Unhealthy': a systematic analysis of alignment between the Australian dietary guidelines and the health star rating system. Nutrients. 2018;10(4).

45. Dunford EK, Huang L, Peters SAE, Crino M, Neal BC, Ni MC. Evaluation of alignment between the health claims nutrient profiling scoring criterion 
(NPSC) and the health star rating (HSR) nutrient profiling models. Nutrients. 2018;10(8).

46. World Health Organization. Healthy diet 2018. https://www.who.int/ news-room/fact-sheets/detail/healthy-diet. Accessed 6 Jan 22.

47. Government of Canada. Regulations amending certain regulations made under the food and drugs act (nutrition symbols, other labelling provisions, Partially Hydrogenated Oils and Vitamin D) 2018. http://gazette.gc. ca/rp-pr/p1/2018/2018-02-10/html/reg2-eng.html. Accessed 6 Jan 22.

48. Ballinger GA. Using generalized estimating equations for longitudinal data analysis. Organ Res Methods. 2004;7(2):127-50.

49. Sacks G, Mialon M, Vandevijvere S, Trevena H, Snowdon W, Crino M, et al. Comparison of food industry policies and commitments on marketing to children and product (re) formulation in Australia, New Zealand and Fiji. Crit Public Health. 2014;25(3):299-319.

50. Vandenbrink D, Pauzé E, Potvin KM. Strategies used by the Canadian food and beverage industry to influence food and nutrition policies. Int J Behav Nutr Phys Act. 2020;17(1):3.

51. Scott C, Hawkins B, Knai C. Food and beverage product reformulation as a corporate political strategy. Soc Sci Med. 2017;172:37-45.

52. UK Health Forum. Public health and the food and drinks industry: the governance and ethics of interaction. Lessons from research, policy and practice. London: UKHF; 2018.

53. Trieu K, Neal B, Hawkes C, Dunford E, Campbell N, Rodriguez-Fernandez $R$, et al. Salt reduction initiatives around the world - a systematic review of Progress towards the global target. PLoS One. 2015;10(7):e0130247.

54. Hyseni L, Bromley H, Kypridemos C, O'Flaherty M, Lloyd-Williams F, Guzman-Castillo M, et al. Systematic review of dietary trans-fat reduction interventions. Bull World Health Organ. 2017;95(12):821-30G.

55. Health Canada. Guidance for the food industry on reducing sodium in processed foods. 2012. https://www.canada.ca/en/health-canada/ services/food-nutrition/legislation-guidelines/guidance-documents/ guidance-food-industry-reducing-sodium-processed-foods-2012.html. Accessed 21 Jun 2021

56. Canadian Food Inspection Agency. Notice of modification: Prohibiting the use of partially hydrogenated oils (PHOs) in foods 2019. http://www inspection.gc.ca/food/requirements/food-safety-standards-guidelines/ notice-of-modification-phos/eng/1536939719584/1536939792275. Accessed 21 Jun 2021

57. Trans Fat Task Force. TRANSforming the food supply: report of the Trans Fat Task Force. https://www.canada.ca/en/health-canada/services/nutri ents/fats/task-force-trans-fat/transforming-food-supply-report.html. Accessed 21 Jun 2021

58. Health Canada. Voluntary sodium reduction targets for processed foods 2020-2025. 2020. https://www.canada.ca/en/health-canada/services/ food-nutrition/healthy-eating/sodium/sodium-reduced-targets-20202025.html. Accessed 21 Jun 2021.

59. Health Canada. Toward the prohibition of partially hydrogenated oils in the Canadian food supply. 2016. https://www.canada.ca/en/healthcanada/programs/banning-partially-hydrogenated-oils-in-foods/consu Itation-document.html\#a11. Accessed 21 Jun 2021.

\section{Publisher's Note}

Springer Nature remains neutral with regard to jurisdictional claims in published maps and institutional affiliations.

Ready to submit your research? Choose BMC and benefit from:

- fast, convenient online submission

- thorough peer review by experienced researchers in your field

- rapid publication on acceptance

- support for research data, including large and complex data types

- gold Open Access which fosters wider collaboration and increased citations

- maximum visibility for your research: over $100 \mathrm{M}$ website views per year

At BMC, research is always in progress.

Learn more biomedcentral.com/submissions 